\title{
MUJERES PERUANAS EN LAS REGIONES DEL NORTE DE CHILE: APUNTES PRELIMINARES PARA LA INVESTIGACIÓN
}

\author{
Menara Lube Guizardi ${ }^{1}$ y Alejandro Garcés $\mathrm{H}^{2}{ }^{2}$
}

\section{$*$ Introducción}

Resumen

La migración Perú-Chile se incrementó fuertemente desde 1995. Las mujeres peruanas son las cabezas-de-red migratoria y los vínculos articuladores entre las localidades de origen y destino. Las condiciones de vida y trabajo de estas migrantes han sido abundantemente estudiadas en la ciudad de Santiago. Sin embargo, la visibilidad dada a la migración femenina peruana en la región Metropolitana es concomitante a la casi inexistencia de estudios sobre el fenómeno en las regiones de Arica-Parinacota, Tarapacá y Antofagasta. El presente artículo indaga las razones por las que la migración peruana en la frontera norte chilena es invisibilizada en el discurso académico. Además, aportaremos datos censales sobre las mujeres migrantes peruanas en el Norte Grande, comparando estas informaciones con aquellas encontradas en Santiago. Con esto, esperamos tejer reflexiones que sirvan de puntos de partida para nuevos estudios cualitativos sobre la migración femenina en el norte de Chile.

Palabras claves: género - migración peruana - centralismo - fronteras nacionalismo. The Peruvian migration to Chile has increased sharply from 1995 onward. Peruvian women have become the heads of the migratory networks, being also the articulation between origin and host societies. The life and labor conditions of these women have been abundantly researched by case studies carried on in the urban context of Santiago. Nevertheless, the visibility given to the Peruvian feminine migration in the city of Santiago is concomitant to the almost inexistence of case studies about the phenomenon in the northern regions of Arica-Parinacota, Tarapacá and Antofagasta. This paper questions the reasons why the Peruvian migration in the Chilean northern frontier is shadowed in the social scientist's discourses. It also analyzes the census demographic data regarding Peruvian migrants in the north of Chile, comparing this profile with the one of the Peruvian women which migrates to Santiago. We expect to provide elements to establish a few start points for new qualitative studies on the woman migration in Northern Chile.

Key words: Gender - Peruvian migration - centralism - borders nationalism.
El presente texto es parte de los esfuerzos preliminares de dos proyectos de investigación que tienen como tema las migraciones internacionales en regiones del Norte Grande: Arica-Parinacota, Tarapacá y Antofagasta. ${ }^{3}$ En gran medida, la motivación de este escrito se refiere a la necesidad de producir conocimientos de apoyo que permitan situar algunos puntos de partida para el estudio cualitativo de las migraciones femeninas peruanas actuales en el norte chileno. ${ }^{4}$ El objetivo fundamental de este trabajo no es, por lo tanto, aportar un conjunto conclusivo de resultados de investigación acerca del fenómeno migratorio en las regiones del Norte Grande. Lo que pretendemos es, por un lado, organizar informaciones cualitativas sobre los estudios de caso acerca de las mujeres peruanas en Chile, y, por otro lado, ofrecer estadísticas sobre la migración en las tres regiones norteñas -facilitando una especie de generalización estadística que permita contrastar e situar los estudios de caso cualitativos de cara al futuro. De esta manera, el esfuerzo crítico que ofrecemos en el presente texto es un paso inicial en el sentido de organizar ideas, estudios y construcciones teóricas que permitan constituir un punto inicial de debate. Comprendemos que los conocimientos científicos se construyen de manera acumulativa, proceso que presupone o requiere la operación de rupturas epistemológicas y metodológicas que permitan, redimensionar y criticar el mismo proceso de constitución del saber. Así, el presente trabajo apuesta por ofrecer un elemento más en el proceso de acumulación de los conocimientos sobre las migraciones internacionales en la región de la triple frontera andina. Una región que, como explicaremos en

Recibido: junio 2012. Aceptado: septiembre 2012.

\footnotetext{
1 Menara Lube Guizardi es investigadora del Centro de Investigaciones del Hombre en el Desierto (CIHDE). Antofagasta 1520, IAI/UTA. Arica, CHILE.Email: mguizardi@cihde.cly menaraguizardi@yahoo.com.br.
} 
el Apartado 3, no ha sido suficientemente estudiada en lo que se refiere a las condiciones actuales de la migración internacional que en ella se produce.

Elaboramos el presente texto centrándonos en atender a cuatro objetivos específicos. En un primero momento, queremos ofrecer una revisión sobre algunas cuestiones teóricas relevantes que han sido abordadas en el marco de los estudios acerca de las migraciones femeninas en América Latina. Este es el tema del Apartado 2, en el que recuperamos debates, cuestionamientos y posiciones asumidas por investigadores/as que han trabajado la migración peruana en Chile y en otros espacios del globo, intentando con esto situar algunos puntos fundamentales a ser tomados en consideración por futuros estudios cualitativos en el norte chileno. Este apartado ofrece una síntesis de los análisis sobre la intersección entre género, desigualdad social, globalización y migraciones femeninas, no pretendiendo, sin embargo, agotar el tema (sino más bien situar cuestiones clave).

Nuestro segundo objetivo es ofrecer una revisión de los estudios sobre las mujeres peruanas en Chile. Esta revisión, no obstante, no está centrada en la idea de operar una descripción pormenorizada de todos los estudios existentes sobre el tema. Nuestra revisión de estos textos está orientada a partir del propósito crítico de comprender si estos estudios ilustran, efectivamente,

\footnotetext{
2 Alejandro Garcés H. es académico del Instituto de Investigaciones Arqueológicas y Museo, Universidad Católica del Norte. Gustavo Le Paige, 380, San Pedro de Atacama, CHILE. Email: ajgarces@ gmail.com; agarces@ucn.cl.

3 Los dos proyectos a que nos referimos son el FONDECYT 11121177: "Conflictos de género, inserción laboral e itinerarios migratorios de las mujeres peruanas en Chile: un análisis comparado entre las regiones de Arica-Parinacota, Tarapacá y Valparaíso" (dirigido por Menara Guizardi); y el Proyecto FONDECYT 11110246 "Etnicidady procesos translocales en espacios de frontera: migraciones internacionales en el norte de Chile" (dirigido por Alejandro Garcés).

4 Desde noviembre de 2011 llevamos a cabo trabajo de campo cualitativo en diferentes ciudades del norte de Chile. La investigación se constituye así como un proceso etnográfico y multisituado (Marcus, 1995), realizado a partir de observaciones y entrevistas en distintos espacios sociales de las urbes de Arica, Iquique Antofagasta y Calama. El lector notará que en algunos momentos del texto mencionamos informaciones que recopilamos en el proceso cualitativo de nuestra investigación (retomando citas, comentarios e historias relatadas por mujeres peruanas).
}

la migración de mujeres peruanas en Chile, y si sus argumentos permiten o no constituir un cuadro claro de los contornos de este fenómeno en el norte del país. Este es el tema que tratamos en el Apartado 3, donde operamos una lectura crítica de estos estudios, observando en ellos algunas distorsiones analíticas que deberíamos evitar de cara a planificar, proponer y ejecutar nuevos estudios de caso sobre el tema. Quisiéramos hacer hincapié en que nuestra postura crítica no desconoce o desmerece los trabajos que hemos revisado. Comprendemos que estos estudios constituyen una importante y sólida base de la que tenemos que partir. Nuestra crítica es, en este sentido, un esfuerzo por contribuir al proceso de construcción del conocimiento, introduciendo matices y cuestionamientos que pretenden ayudar a sumar esfuerzos en el marco de los estudios sobre migración en el contexto latinoamericano.

El tercer objetivo de este texto (Apartado 4) es ofrecer la revisión de estadísticas censales sobre las mujeres peruanas en las tres regiones objeto de nuestro recorte de estudio. Comprendemos que las estadísticas censales son una medida poco exacta para la medición de poblaciones migrantes (por ejemplo, difícilmente logran captar o representar a las personas en condición de indocumentación). No obstante, apostamos por hacer recortes regionales de las estadísticas censales pensando que este ejercicio puede ofrecer - pese a las distorsiones que en él puedan existir- un parámetro de comparaciones y unos índices de observación del fenómeno. Pensamos que este ejercicio es importante también en el sentido de preparar los datos para la comparación con los resultados del censo chileno realizado en 2012 (cuyos resultados serán publicados a lo largo de 2013). Así, partimos del supuesto que las estadísticas no constituyen una herramienta perfecta para el estudio del fenómeno migrante en el Norte Grande, sin embargo consideramos que la recopilación de datos sobre la escolaridad, vinculación étnica, e inserción laboral de las mujeres peruanas puede ofrecer un material de soporte que sirva de apoyo al desarrollo de investigaciones cualitativas. En estudios sobre el fenómeno migrante es de fundamental importancia jugar con las escalas de observación, desplazando el análisis del plano macro al micro y vice-versa. Con las estadísticas, esperamos aportar elementos que ayuden a componer una mirada macro que, no obstante, debe ser contrastada con las perspectivas cualitativas, puesto que las generalizaciones que desde los 
datos se pueden tejer no siempre logran captar la complejidad de la experiencia de las mujeres migrantes

Nuestro último objetivo (Apartado 5) es relevar preguntas y temas de investigación de cara al futuro, apuntando campos, ejes y temáticas sobre las mujeres migrantes peruanas en el norte, que debieran ser trabajadas a nivel cualitativo. Esperamos con esto estimular la imaginación y el espíritu crítico de los lectores, consolidando caminos que permitan el desarrollo de nuevos estudios de caso sobre la migración en el Norte Grande.

\section{* Género, migraciones, desigualdad SOCIAL Y GLOBALIZACIÓN DEL TRABAJO REPRODUCTIVO: EL CASO PERUANO EN EL MARCO DE UN PROCESO REGIONAL LATINOAMERICANO ${ }^{5}$}

Las mujeres constituyen por vía de regla las cabezas de las redes migratorias peruanas (Araujo et al. 2002; MartínezPizarro 2003, 2007, 2009; Stefoni 2009; Tijoux 2007). Esta es una tendencia muy generalizada entre diferentes países del contexto regional latinoamericano, donde las mujeres son quienes inician el proceso de desplazamiento internacional (Lipszyc 2004) que terminará por movilizar a una parte extendida de sus comunidades de origen, constituyendo por ende los puntos nodales de unas redes sociales que tienden a transnacionalizarse progresivamente (Alicea 1997; Nyberg 2008; Pedone 2011). Así, estas migrantes articulan familias organizadas sobre diferentes territorios nacionales, reinventando no solamente los procesos de crianza de hijos/as (Aranda 2003; HondagneuSotelo y Ávila 1997), sino que también actuando a manera de globalizar sus localidades de origen. Las vidas diarias de estas mujeres dependen de múltiples y constantes interconexiones que cruzan fronteras internacionales, puesto que sus identidades, afectos, y su inserción socioeconómica se configuran relacionándose siempre con más de un EstadoNación. De ahí que podamos considerarlas sujetos transnacionales, en los términos de Glick-Shiler y colboradores (1995: 48). ${ }^{6}$ Por otro lado, su protagonismo migratorio

\footnotetext{
5 Una versión previa de este texto fue presentada al Comité de Organización del V Congreso de la Asociación Latinoamericana de Población, Montevideo, Uruguay, 23 al 26 de octubre de 2012.

6 Según las mismas autoras, la migración transnacional se definiría
}

también implica que ellas asumirán el papel de motor de una actividad económica (Paerregaard 2006) que impactará la manera cómo las familias se constituyen, las relaciones maritales, el papel social atribuido a abuelos/as, tíos/ as y amigos/as en el contexto familiar. Esto ocurre porque cabrá a estos parientes y amigos/as hacerse cargo de parte de la educación de los hijos/as de las mujeres migrantes, o por lo menos cuidar el gasto y uso de las remesas, asumiendo consecuentemente nuevas funciones en el marco de la vida cotidiana de estos menores. Para el caso de la migración peruana que nos ocupa aquí, estudios en diferentes países del mundo han comprobado esta tendencia a la feminización de la cadena migratoria y la importancia de la figura de las mujeres en la creación/mantención de los vínculos y redes transnacionales.? Según Paerregaard, "la participación femenina en la emigración peruana no es un fenómeno nuevo. Al contrario, las mujeres han tomado el papel de punta de lanza de la emigración peruana a países como Estados Unidos, España, Italia, Argentina y Chile desde hace muchos años" (Paerregaard 2006: 64).

Este fenómeno de feminización de las migraciones que se ha generalizado en América Latina (Stefoni 2009),

como "el proceso según el cual los migrantes construyen y mantienen, simultáneamente, relaciones sociales multilocalizadas que les conectan a su sociedad de origen y a su sociedad de residencia. Al identificar los procesos de migración transnacional, estamos enfatizando los coetáneos y continuos caminos por los cuales los inmigrantes, en el día a día, construyen y reconstruyen su simultánea afiliación a más de una sociedad" (Glick Schiller et al. 1995: 48). La mantención de estos vínculos con las localidades de origen puede constituirse como una forma de resistencia política, en la medida en que ellos son vividos o apropiados por algunas mujeres migrantes como una estrategia para enfrentar opresiones étnicas, de clase y de género sufridas en los contextos de acogida (Alicea 1997). Pero también es cierto que para algunas mujeres migrantes su situación transnacional no implica una ruptura con relaciones de poder asimétricas en las sociedades de origen. Recomendamos en este sentido el libro editado por Rivas y González (2010) sobre las familias transnacionales colombianas. Las autoras han observado que las remesas transnacionales de las mujeres colombianas en España actuaban más bien reproduciendo la jerarquía de género, incidiendo en una centralidad masculina acerca del uso del dinero, en algunos casos, y agravando la súper-explotación del trabajo femenino en el contexto familiar.

7 Para el caso español, véase Escrivá (2005) y Parella (2007); para Argentina, Gerbaudo-Suárez et al. (2010), Paerregaard (2005); para Chile, Godoy (2007), Núnez y Hoper (2005), Stefoni (2002, 2005); para Italia, Tamagno (2005). 
sin embargo, va más allá de este contexto geográfico específico, consolidándose como una realidad a escalas globales (Godoy 2007; Mora 2008). La intensificación de los flujos humanos -y la feminización progresiva de éstos - se encuentra asociada a una nueva fase del sistema capitalista, "caracterizada por la internacionalización de la producción, la concentración del capital, las nuevas formas de acumulación flexible y el declive de la importancia del Estado-Nación en la gestión y planificación económico-política" (Pizarro 2011: 6) -lo que Castles y Miller (2004) sintetizaron con la frase: la era de la migración. A la vez, la condición migrante da materialidad a los procesos de fragmentación del capitalismo avanzado: una fragmentación estructurada mediante marcadores de etnicidad que ubican las poblaciones en niveles diferenciales de acceso y derecho a recursos. Las poblaciones migrantes están crecientemente limitadas por su "asignación diferencial a posiciones sociales con base a criterios étnico-sociales" (Pizarro, 2011: 7).

También desde un punto de vista económico global, esta movilidad femenina está profundamente vinculada a un mecanismo de internacionalización del trabajo reproductivo (Solé y Parella 2005). Al ocupar el trabajo reproductivo -muy a menudo acotado a la esfera doméstica- las migrantes latinoamericanas en todo el mundo $-y$ en este amplio grupo, las peruanas en Chile- son protagonistas de un proceso de globalización de los servicios del cuidado (Arriagada y Moreno 2011). El mercado de los "servicios del cuidado" se ha generado históricamente en las sociedades en las que las mujeres autóctonas empiezan a desarrollar funciones económicas productivas (Staab y Maher 2006; Stefoni 2002). Como esta salida femenina al mundo productivo generalmente no viene acompañada de la re-organización de las tareas de reproducción del hogar entre hombres y mujeres, se genera una demanda por otras mujeres que se ocupen del trabajo reproductivo. Es justamente este sector laboral el que aparece como una alternativa a las mujeres migrantes. Así, las migrantes se encasillan en un nicho social y laboral, estando expuestas a drásticos procesos de precarización de su mano-de-obra (Magliano y Romano 2011). Esta realidad ha sido ilustrada por diversas autoras estudiando las condiciones de vida y trabajo de las peruanas en Santiago de Chile (Alman 2011; Arriagada y Moreno 2011; Lahoz 2011; Núñez y Holper 2005; Staab y Maber 2006; Stefoni 2002, 2009; Stefoni y Fernández 2011; Tijoux 2002, 2007, 2011; Godoy 2007;
Lipszyc 2004; Pavéz-Soto 2010; Setién y Acosta, 2011). Se trata pues, de una inserción socio-económica que reordena a escalas globales los sistemas de explotación y las jerarquías de género (Mills 2003); ambos factores muy impactados por las definiciones de desigualdad basadas en la adscripción étnica, de clase, de edad y de pertenencia nacional que definen los espacios, derechos y posibilidades de incorporación social de las mujeres que migran (Pizarro 2011; Méndez y Cárdenas 2012). Es bastante conocido en la literatura en ciencias sociales -tanto la que versa sobre las migraciones internacionales latinoamericanas en general, como la que versa sobre el caso de las mujeres peruanas en Chile- que este proceso de feminización del desplazamiento humano desencadena toda una complejidad de conflictos de género. Estos conflictos son multidimensionales, involucrando simultáneamente diversos elementos (Lipszyc 2004):

\section{Elementos de orden simbólico}

Relacionados con la estructura patriarcal, patrilineal y paternalista de las sociedades de origen y destino (Martínez-Labrín 2006). La asunción de un cierto protagonismo económico por parte de estas mujeres debido a su experiencia migratoria les permite algún nivel de independencia frente a las relaciones de subordinación a las que muy frecuentemente están expuestas en el contexto de origen. El parcial distanciamiento facilitado por el desplazamiento les permite cuestionar y re-significar las estructuras de dominación masculinas (Wagner 2008), lo que por otro lado resulta en dinámicas de "tira-afloja" de las relaciones con las parejas, con los hijos y con las comunidades de origen. De esta manera, las estructuras simbólicas de justificación de la subordinación femenina y las ideologías de género se ven, en algunos casos, fuertemente cuestionadas y tensionadas (Aranda 2003). En otros casos, no obstante, se ven reforzadas y reproducidas. Estos procesos desencadenan transformaciones agudas en la manera como las comunidades de origen de estas mujeres estructuran su vida social: desde la división social del trabajo, pasando por el lenguaje, por las alianzas entre familias y llegando en la misma configuración política a nivel local y en algunos casos nacional.

\section{Aspectos económicos}

La precariedad laboral de estas mujeres en origen condiciona, en muchos casos, una mayor flexibilización de su 
trabajo y la asunción de funciones laborales normalmente vinculadas a un mercado de trabajos domésticos (limpieza, cocina, cuidado de menores y ancianos) (Lipszyc 2004; Setién y Acosta 2011). El trabajo doméstico representa en América Latina un sector laboral marcado por la vulnerabilidad: con bajas remuneraciones, reincidencia de abusos por parte de los empleadores, escasa protección social y elevados niveles de informalidad (Mora y Valenzuela 2009; Rodgers 2009; Loyo y Velázquez 2009; Stefoni 2009, 2011). En algunos casos, es la precariedad laboral en origen lo que "prepara" a las mujeres para asumir este mismo mercado laboral en destino, ayudándoles a constituir unos conocimientos y prácticas en relación al trabajo informal que serán la base de su experiencia económica migratoria. En muchos casos, sin embargo, las mujeres inmigrantes están sobre-cualificadas para los servicios a los que consiguen acceder en destino: muchas cuentan con una escolaridad superior a la media de las mujeres autóctonas, y otras cuantas dejan trabajos que exigen formación técnica en sus países de origen, para asumir funciones que no exigen cualificación profesional. Sea como fuera, estas mujeres migrantes, al hacerse cargo del trabajo reproductivo de las familias autóctonas, pasan a constituir una mano de obra complementaria fundamental en países como Chile (Acosta 2011; Arriagada y Moreno 2011; Araujo et al. 2002; Tijoux 2007; Setién y Acosta 2011; Stefoni 2005). La existencia de este creciente mercado laboral para los trabajos de reproducción en Chile (Paerregaard 2006; Stefoni 2009) hace de las mujeres peruanas el pilar de la actividad económica de sus familias (Lipszyc 2004; Stefoni 2009): una función históricamente masculina en las sociedades patriarcales. Su protagonismo económico provoca la complejización de su función económica intrafamiliar. Pero, pese a que estas mujeres ganen en alguna medida un espacio en el mundo productivo (normalmente entendido como "masculino" en oposición a una supuesta "feminización" de los quehaceres reproductivos), su aportación económica puede terminar resultando en una consolidación de las jerarquías de género, reforzando una normatividad patriarcal. Esto lo han constatado investigadoras como Tapia y colaboradores (2010) observando la manera como las remesas de mujeres migrantes colombianas en realidad reproducían asimetrías de género, actualizando fuertemente la explotación femenina en el marco de las relaciones familiares en un contexto transnacional. No obstante, estas mismas autoras observan que la aportación económica de las mu- jeres migrantes permite un nivel de movilidad social para sus hijos, en la medida en que incide muy generalmente en el financiamiento de los estudios de éstos jóvenes.

\section{Aspectos religiosos}

Se observa la transformación y re-significación de valores religiosos en el proceso de asunción de nuevos roles sociales vividos por estas mujeres, lo que en gran medida implica la dificultad de mantener vínculos permanentes con las congregaciones religiosas en origen y el cuestionamiento de los valores religiosos en su función ilustrado$\mathrm{ra} /$ mantenedora de los roles de género. Al mismo tiempo, son justamente las congregaciones religiosas en destino, normalmente vinculadas a la Iglesia católica, las que prestan asistencia a las poblaciones migrantes, siendo por lo tanto un importante referente de acogida en los países como Chile, donde la neoliberalización del Estado eliminó servicios sociales de asistencia a la población marginada. De esta manera, tenemos un paradójico acercamiento a las organizaciones religiosas de atención a los migrantes en la sociedad de destino, acompañado de una dificultad de mantener las vinculaciones religiosas en origen. Para el caso de las mujeres pertenecientes a grupos indígenas con una adscripción religiosa más fuertemente anclada en la identidad colectiva de su etnia, esta necesidad de amparo por parte de instituciones católicas puede vivirse como una presión por asumir valores religiosos cristianos y/o católicos, englobándose como parte de los fenómenos que Walter Mignolo (1996) denominaría "neocolonialismos".

8 Por otro lado, como bien apunta Asunción Merino (2003: 738), la adhesión a identidades universalizantes como el "ser católico" puede significar un importante recurso para la constitución de afinidades identitarias entre migrantes. El autor constató, en su estudio de caso, cómo las hermandades organizadas por migrantes de Perú y dedicadas al señor de los Milagros en la ciudad de Madrid (España) cumplían el importante papel de generar una experiencia de pertenencia colectiva entre inmigrantes peruanos provenientes de diferentes regiones y de diferentes sectores sociales. Esto nos hace plantear que la complejidad de los procesos de afiliación religiosa de los/as migrantes en el norte de Chile requiere estudios cualitativos que permitan observar los papeles jugados por la religiosidad en la experiencia cotidiana de los sujetos. Este sería uno de los campos de estudios a los que dedicar atención en futuros trabajos sobre el tema migrante en el Norte Grande -y que ayudaría a entender con más profundidad el tipo relación establecida por las mujeres en el marco de la atención prestada a migrantes por organizaciones religiosas cristianas. 


\section{Aspectos étnico-raciales}

Vinculados a la manera como estas mujeres son identificadas, clasificadas y frecuentemente discriminadas en las sociedades de destino debido a su supuesta adscripción a una etnicidad indígena, lo que es bastante recurrente en el caso de las peruanas en Chile (Méndez y Cárdenas 2012; Poó 2009; Stefoni 2005; Tijoux 2002, 2007, 2011). Las migrantes latinoamericanas en diferentes espacios del globo sufren procesos de discriminación racial que tienden a yuxtaponer su supuesta identidad étnicoracial a su función/inserción económica (Escrivá 2005; Parella 2003, 2005; Magliano y Romano 2011; Pedone 2011). Este mecanismo de etiquetaje social produce una vinculación entre rasgos culturales y supuestamente biológicos a la asunción de determinados roles laborales (Parella 2005). Así, la subordinación económica de estas mujeres, la asunción de trabajos precarizados, su exclusión documental, social y económica en las sociedades de destino, tienden a confundirse ( $y$ en muchos y desafortunados casos a justificarse) a partir de este proceso de discriminación étnico-racial. Estudios realizados con los migrantes peruanos en Santiago en la última década observan que las mujeres peruanas son frecuentemente encasilladas en estereotipos étnicos que no pocas veces carecen de sentido para estas mismas mujeres (Godoy 2007; Núñez y Hoper 2005; Staab y Maber 2006; Tijoux 2002, 2007). Aquí, la migración es el escenario que refuerza el cruce de los elementos de exclusión racial y étnica, con los elementos de exclusión de género y de clase, exponiendo a estas mujeres a una compleja superposición de factores determinantes de la desigualdad social. En este sentido, el estudio de las mujeres peruanas en Chile requiere que se combine tres categorías clave de análisis, las cuales están fuertemente implicadas en la constitución de la marginalidad de las migrantes mujeres: género, clase social y condición étnica, como bien lo afirman Araujo et al. (2002), Lipszyc (2004), Méndez y Cárdenas (2012), Stefoni (2002, 2009) y Tijoux (2007). Todas estas autoras, a excepción de Lipszyc (2004), se amparan en los análisis sobre clase, raza y género de Wallerstein y Balibar (1991). Desde nuestro punto de vista, la articulación entre clase social, etnicidad y condición migratoria se construye a partir de la aplicación transversal del enfoque de género. Por enfoque de género, comprendemos la perspectiva empírico-epistemológica de que las desigualdades de género operan, simultáneamente, como sistemas de significados y simbolismos dominantes; como relaciones sociales estructuradas, roles, y prácticas; y como prácticas cotidianas de identidad social. En este sentido, concordamos con las consideraciones de Mills de que:

"Los sentidos, relaciones y identidades de género hacen más que sencillamente sostener estructuras ya existentes de poder en las relaciones laborales globales; estas complejas dimensiones de género también constituyen un terreno cultural dinámico donde las formas de dominación pueden ser contestadas, re-trabajadas y transformadas" (Mills, 2003: 42).

Alrededor del mundo, las jerarquías de género son producidas y mantenidas en relación con los circuitos transnacionales que "movilizan la mano de obra y la acumulación del capital. A partir de formas variadas, y casi siempre localmente específicas, el capital internacional se apoya en las ideologías de género para reproducir y hacer más barata la segmentación de la fuerza laboral dentro y a través de las fronteras nacionales" (Mills 2003: 43). Esto no significa que la segmentación y jerarquización operada a partir de la condición étnica y de clase no opere en las mujeres migrante. Significa más bien que estos encasillamientos sociales son demarcados de manera sui generis debido a la condición de género de éstas mujeres, operando en ellas de manera diferente. Esta particularidad de la condición femenina tiene que ver con una dimensión global del sistema de explotación de la mano de obra, y remite al hecho de que la flexibilización y el desplazamiento de la mano de obra migrante femenina se da según patrones ideológicos diferentes de aquellos que operan con los hombres.

\section{* Los estudios de caso sobre mujeres PERUANAS EN CHILE: Distorsiones} ANALÍTICAS Y NACIONALISMOS METODOLÓGICOS

La literatura de las ciencias sociales sobre la migración peruana en Chile ha estudiado abundantemente las condiciones generales de vida y trabajo de las/os peruanas/ os llevando a cabo investigaciones localizadas fundamentalmente en la ciudad de Santiago. ${ }^{9}$ Estos estudios

\footnotetext{
9 Araya (2007), Ducci y Rojas (2010), Luque (2004; 2007), Schiappacasse (2008) y Garcés (2007, 2011, 2012) abordaron
} 
han traído a la luz una perspectiva panorámica acerca de la experiencia de las mujeres peruanas que permite correlacionar el fenómeno con las condiciones macro-sociales del desplazamiento femenino (tanto en términos intrarregionales en América Latina, como en términos globales). Ellos aportan, además, una masa importante de datos cualitativos a partir de los cuales podemos llegar a dibujar un cuadro bastante preciso sobre la experiencia social migratoria de estas mujeres en el contexto de la región Metropolitana de Chile. Sin embargo, pese a la diversidad de los estudios de caso sobre las migrantes peruanas llevados a cabo en la última década $-y$ pese a la incuestionable calidad de estos trabajos-encontramos tres importantes distorsiones analiticas que se repiten en la gran mayoría de estas investigaciones.

La primera de las distorsiones se refiere justamente a la operación de los recortes espaciales, correspondiendo por ende a una insuficiencia de orden metodológico y epistemológico. Observamos en este sentido que las investigaciones sobre migración peruana eligen como espacio sine qua non de estudio la capital chilena. En realidad, solamente tres estudios han investigado la actual migración femenina en las zonas de la frontera norte: Méndez y Cárdenas (2012), Erazo (2009) y Tapia y Gavilán (2006), y solamente el estudio de Martínez-Labrín (2006) abordó el tema en el sur del país (en la ciudad de Concepción).

\footnotetext{
la construcción de territorialidades, enclaves, centralidades y segregación espacial de los peruanos en Santiago. Las relaciones de género y la inserción social de las mujeres peruanas en los servicios domésticos de la capital motivaron los estudios de Núñez y Holper (2005); Staab y Maber (2006); Stefoni (2002, 2009); Stefoni y Fernández, (2011); Tijoux (2002, 2007), Godoy (2007), Lipszyc (2004), Pavez-Soto (2010); Setién y Acosta (2011); Arriagada y Moreno (2011) y Alman (2011). La dimensión política de la migración peruana en Santiago - desde el punto de vista del asociativismo inmigrante, del acceso a ciudadanía, o de los deficitarios marcos jurídicos y políticas públicas- son trabajadas por Jensen (2009, 2010), Luque (2005, 2007, 2009), Navarrete (2007) y Stefoni (2005). Mujica (2004) y Cabib y Mora (2011) estudiaron las condiciones generales de trabajo y movilidad socioeconómica. La inclusión/exclusión de los hijos/as de migrantes peruanos en colegios de la región Metropolitana fue investigada por Poblete (2006), mientras Núñez (2011) y Núñez y Torres (2007) abordaron la salud reproductiva de las peruanas en los centros de salud santiaguinos.
}

Esta elección del recorte espacial centrado en la capital del país se justifica de diversas maneras por los investigadores: sea porque en números absolutos Santiago presenta la mayor concentración de migrantes peruanos; sea porque los migrantes peruanos desarrollaron una interesante apropiación del espacio público urbano en la región Metropolitana; o bien porque hay una expresiva cantidad de mujeres peruanas empleadas en los servicios del hogar en familias de clase media y alta en el sector oriente de la ciudad -lo que les genera un nicho laboral específico que es cada vez más visible en términos sociales. Más allá de la validez de todos estos argumentos, y pese al hecho de que algunos de ellos sean cuestionables, ${ }^{10} \mathrm{el}$ problema de este foco excesivo en Santiago se refiere más bien a que la mayoría de los investigadores publican los resultados de estas investigaciones considerándolos válidos para todo Chile. Se ha generalizado el uso de la expresión "migración peruana en Chile" como definidora de los estudios de caso llevados a cabo únicamente en la capital. Esto no significa que las conclusiones y realidades descritas por estos estudios no podrían ser expresivas de lo que ocurre con las migrantes peruanas en otras regiones del país. Significa que en ningún caso estas informaciones debieran ser tomadas como "automáticamente válidas" para las demás regiones, sin que estuvieran respaldadas por estudios empíricos. Lo que notamos en el uso discursivo de la expresión "en Chile" por parte de los estudios realizados en Santiago es un proceso acrítico de asunción de que la migración peruana femenina en la capital representa (o es significativa de) lo que ocurre en todo el territorio nacional. Este efecto metonímico que toma Santiago por Chile constituye la segunda importante distorsión analítica que observamos en los estudios de la migración peruana.

La tercera de las distorsiones analíticas se refiere a otro tipo de proceso de nacionalización, operado ahora no en relación al territorio de Santiago, pero fundamentalmente en relación a las propias migrantes peruanas. Se observa en los estudios sobre el fenómeno en la región

\footnotetext{
${ }^{10}$ En la epígrafe 3 explicamos cómo el argumento acerca de la importancia numérica de la migración peruana en Santiago debe ser relativizado considerando sobre todo que las regiones del norte de Chile son menos densamente pobladas y que debido a esto, la presencia peruana es más relevante a niveles relativos, es decir, comparada con los contingentes totales de población censada en estos territorios.
} 
Metropolitana una asunción tácita de que las mujeres peruanas que ahí se encuentran son representativas de "todas las mujeres peruanas en Chile". Así, los investigadores hacen un paso de nacionalización semejante a lo que se verifica en el caso de la nacionalización del territorio de Santiago, pero ahora nacionalizando como "peruano" el perfil de las mujeres migrantes estudiado en la capital chilena. A la vez que Santiago se convierte en "Chile", las peruanas en Santiago se convierten en representativas de todo el Perú. Se trata de una reducción de la mirada que homogeniza el colectivo migrante, asumiendo que hay un grupo fijo de características que definen al perfil de estas mujeres entrevistadas en Santiago, y que estas características son, en última instancia "peruanas": contenedoras de unos supuestos rasgos nacionales de carácter, condición económica y realidad sociocultural.

Estas distorsiones analíticas - la que "chileniza" a Santiago y la que "peruaniza" a las mujeres estudiadas en la capital chilena- incurren en lo que Levitt y Glick-Schiller denominaron nacionalismos metodológicos, es decir, "la tendencia a aceptar el Estado-Nación y sus fronteras como un elemento dado en el análisis social" (2004: 65). Como mencionan las autoras, este nacionalismo metodológico se expresa a través de tres variables, todas ellas verificables en los estudios de la migración peruana en Santiago: 1) el ignorar o menospreciar la importancia del nacionalismo en las sociedades modernas; 2) el naturalizar o dar por sentado las fronteras del Estado, y 3 ) el confinar el estudio de los procesos sociales a las fronteras político-geográficas de un Estado particular (Levitt y Glick-Schiller 2004: 65). ${ }^{11}$ Desde nuestro punto de vista, sin embargo, en el caso de los estudios sobre migrantes peruanos "en Chile", es la primera variable la que condiciona el desarrollo de las

\footnotetext{
${ }^{11}$ Este último punto es especialmente importante. Pese a que muchos de los trabajos sobre mujeres migrantes en Santiago hablen de la dimensión transnacional de éste fenómeno; pese a que la casi totalidad de los autores asuman un marco teórico-epistemológico que comprende las migraciones actuales como parte de los flujos y rupturas transnacionales del capitalismo actual, no encontramos ninguno ejemplo de investigación que realice trabajo de campo en los sitios de origen en Perú, o que en otra medida, se proponga a relativizar la relación entre el espacio de Santiago y el grupo estudiado, buscando para ello técnicas y métodos de investigación multisituada, que desde hace por lo menos veinte años son usados en los estudios de grupos migrantes transnacionales (véase en este sentido el clásico texto de Marcus 1995 y el de Burawoy 2000).
}

otras dos, puesto que observamos en estos estudios una reincidente desatención al significado de la capital Santiago como epicentro del proyecto nacional chileno. Como comentó Stefoni (2005) en su momento, la migración peruana en Santiago tiene un especial impacto en los imaginarios nacionalistas chilenos fundamentalmente porque ocupa un espacio que históricamente ha identificado a peruanos y bolivianos como los "otros" de una supuesta identidad blanca y "no-indígena" chilena. ${ }^{12}$

Aquí, la operación metonímica que identifica el "otro peruano" como un "indio" opera en una clasificación política que es el reflejo de la dominación colonial: reflejo de cómo el colonialismo en cuanto estructura de producción de otredades y jerarquías de poder se actualiza a diario en la conformación de las ideologías de pertenencia nacional en Chile. Tal categoría, "indio", conjuga simultáneamente aspectos biológicos (raciales y racistas) y culturales, y es producto de la subordinación y negación de la humanidad de un grupo frente a otro que se construye como blanco, europeo (o eurodescendiente) y superior (Bello y Rangel 2002: 40). En este sentido, la migración despierta y visibiliza los discursos hegemónicos del proyecto de construcción del Estado-Nación en Chile, como es la idea de que el país es una "excepcionalidad" en el contexto latinoamericano y que su supuesto "blanqueamiento" y "modernidad" le hacen contrastar con los vecinos Bolivia y Perú (Staab y Waher 2006: 88-89), posicionándolo en un pretendido nivel superior. La visibilización de lo peruano en Santiago -su construcción como "el otro indígena"-,

\footnotetext{
12 Según la autora: "la negación del origen indio como parte de la nación ha derivado no solo en la exclusión y discriminación de los pueblos originarios, sino en que la cultura dominante con un discurso homogeneizante intente barrer la diversidad de las culturas mapuches, aymaras y pehuenches, entre otras. En este sentido, la población indígena en Chile ha sido un 'otro' invisible, sistemáticamente silenciado en la formación de la nación y la identidad chilena. Representa todo aquello que no queremos ser y, por ende, es ocultado y negado. La inmigración andina nos vuelve a enfrentar con nuestra identidad mestiza y nos recuerda aquello que intentamos eliminar a fuerza de olvido. En otras palabras, nos enfrenta con nosotros mismos, ya que ies verdaderamente posible distinguir fenotípicamente un peruano de un chileno?" (Stefoni 2005: 266). Sobre Stefoni cabe subrayar que la autora ha expresado su criticismo acerca de la generalización de la migración peruana en Santiago como representativa del fenómeno a escalas nacionales en más de una ocasión, siendo una excepción entre los diferentes autores que trabajan el tema (véase en este sentido Stefoni 2005).
} 
está profundamente vinculada con los juegos de emergencia y ocultamiento que el paradigma étnico nacional chileno plantea de manera desigual en diferentes espacios regionales de Chile. El discurso hegemónico de una composición poblacional "blanca" en el país ha sido puesto en práctica de manera asimétrica en las diferentes regiones, haciéndose fuertemente presente en el centro, a la vez que adquiriendo matices en la medida en que nos movemos del centro hacia las regiones más periféricas. Aquí, la centralidad de la ideología de pertenencia nacional se encuentra inscrita en su propia metáfora espacial, siendo la región Metropolitana su espacio de más intensa materialidad.

En gran medida, la construcción de la categoría "centro", y la ideología de la primacía de este "centro" como conductor de la normatividad del Estado-Nación en Chile recupera esta construcción de la modernidad europea (Dussel 1994), reinscribiendo a niveles nacionales esta ideología de la conquista que el capitalismo hizo expandir inventando euclidianamente una "geografía internacional": la premisa geográfica que naturaliza la división del globo en naciones (algunas de las cuales centrales, con un supuesto derecho de dominio sobre las que se consideran periféricas y por ende "colonizables"). Este también es un proceso que se observa en la construcción territorial de otros países latinoamericanos, pero en pocos de ellos se da la casualidad de que el "centro" en cuestión coincida con el "centro" espacial del territorio nacional, como ocurre en Chile. Este tipo de reproducción de las lógicas modernas de construcción de la alteridad actúa potenciando la colonialidad de todo saber producido en las naciones donde esta práctica se mantiene. Esta colonialidad del conocimiento dice relación con la mantención histórica de invisibilidades: con el silenciamiento del otro, y con la negación del derecho de diferencia. Dice relación con la visibilización del centro y con su emergencia en cuanto productor de los discursos hegemónicos sobre pertenencia y exclusión. En este sentido, el centralismo chileno es una ideología colonial de otredad, que construye a modo de "colonialismo interno" la justificación del dominio de un centro sobre sus supuestas periferias. Podemos considerar que esta reproducción de formas modernas de explotación y dominación actúa confirmando la colonialidad del poder (Maldonado-Torres 2007: 129): el poder que se reinventa en un patrón colonialmente impuesto a modos de modernidad y, no menos, a modos de desarrollo (el desarrollo de Santiago, una región Metropolitana, versus el subdesarrollo de las periferias, de las "provincias"). ${ }^{13}$ Ahora bien, como bien explicita Mignolo, esta colonialidad del poder se reproduce gracias a su confirmación en un nivel epistémico, es decir, su confirmación como estructura de conocimiento de la experiencia social, como colonialidad del saber (Mignolo 2003: 669). De este modo, las prácticas discursivas que encontramos en el caso de los estudios sobre la migración peruana -que nacionalizan lo que es una realidad del "centro", y que invisibilizan las demás regiones chilenas en su diversidad de otredades posibles- deben ser tomadas en su contenido político último. Este contenido se refiere a que estas son prácticas discursivas que engendran, a través del lenguaje académico de las ciencias sociales, la colonialidad del poder y del saber producido acerca de las relaciones de otredad en Chile.

Así, caminando en un sentido de hacer emerger realidades invisibilizadas por los recientes estudios sobre migración peruana en Chile, nos interesa subrayar no solamente cómo estos nacionalismos metodológicos operan organizando la mirada, el contenido último y la amplitud de los análisis sobre el fenómeno. Nos interesa la otra cara de este proceso, su efecto simultáneo y coetáneo: la invisibilización de otras regiones del país que provocan escaso interés de los investigadores sociales, pese a que en ellas la migración peruana, boliviana y argentina pueda tener unas dimensiones históricas y demográficas diferentes de lo que se observa en el caso de Santiago. Este es el caso para el territorio del norte grande, compuesto por áreas integradas a Chile después de los conflictos bélicos del siglo XIX, habiendo pertenecido históricamente a los vecinos andinos Bolivia y Perú. En gran medida, la migración en las regiones del norte de Chile, sobre todo donde las dos triples fronteras -la andina (Chile-BoliviaPerú), y la circumpuneña (Argentina-Chile-Bolivia) (González-Miranda 2009) - constituye un fenómeno histórico de larga duración que invoca a procesos de movilidad social muy anteriores a la última década del siglo XX (Tápia y Gavilán 2009). ${ }^{14}$

\footnotetext{
13 Para un refinado análisis histórico del centralismo como ideología de las élites santiaguinas, como elemento estructurante del silenciamiento (económico, militar y político) de las demás regiones nacionales, y como principal motivación del control dictato$\mathrm{rial} / \mathrm{militar}$ en la conformación del Estado chileno entre el siglo XIX y XX, véase Gabriel Salazar (2005).

${ }^{14}$ Un ejemplo de la continuidad histórica de la presencia de migrantes originarios de estos tres países, es su masiva llegada al Norte
} 
En el apartado que sigue, desglosaremos los datos estadísticos de los últimos dos censos chilenos (1992 y 2002), aportando informaciones generales sobre la migración femenina peruana en el norte grande. Compararemos estos datos con las estadísticas de la migración peruana en la región Metropolitana, motivados por el interés de visibilizar las posibles especificidades que el colectivo presenta en diferentes espacios del territorio nacional.

* Comparación entre el perfil

SOCIO-DEMOGRÁFICO DE LAS INMIGRANTE

peruanas en el Norte Grande de Chile

(ARICA-PARINACOTA, TARAPACÁ Y

Antofagasta) y en SAntiago

\section{Recortes de la muestra censal}

Antes de dar a conocer los datos estadísticos sobre migración de mujeres peruanas en el norte de Chile, conviene explicitar algunos detalles de orden metodológico referentes al recorte espacial de la muestra y a los criterios de selección y agrupación de los datos. La primera importante observación resulta de la misma división política de las regiones que componen el territorio estudiado. Actualmente, el norte grande se encuentra subdividido en tres regiones político-administrativas: Arica-Parinacota, Tarapacá y Antofagasta, a su vez subdivididas internamente en unidades administrativo-territoriales denominadas "provincias", y estas últimas en unidades denominadas "comunas". La cuestión relevante para nuestro estudio está en que la región de Arica-Parinacota -también conocida como la "XV región"- fue creada en 2007 congregando a comunas que anteriormente pertenecían a la región de Tarapacá. ${ }^{15}$ Así, los censos de 1992 y de 2002 no presentan datos para Arica-Parinacota como región autónoma, pese a que sí presenten las informaciones poblacionales de sus provincias y comunas, estando incorporadas en ambos censos en las estadísticas del antiguo territorio de Tarapacá. Esta circunstancia nos planteó

Grande ocasionada por los ciclos productivos del salitre, en las primeras décadas del siglo XX (González-Pizarro 2008).

${ }^{15}$ La Ley 20.175, que decreta la creación de la región de Arica-Parinacota, fue publicada en Diario Oficial el día 11 de abril de 2007. Para más información, consúltese el documento de "Historia de la Ley", publicado por el Congreso Nacional de Chile en el mismo año de 2007. un problema metodológico importante, ya que la actual división político-administrativa del territorio no coincide con la manera como los datos son presentados por el censo. En este sentido, tomamos la decisión de presentar las estadísticas construyendo "artificialmente" de AricaParinacota. Llevamos a cabo esta construcción recortando en los censos de 1992 y de 2002 las informaciones de las comunas que actualmente componen la región de Arica-Parinacota, y considerando solamente las comunas que actualmente componen a la región de Tarapacá como fuente para las estadísticas demográficas de esta región. Así, cuando nos referimos a la región de Arica-Parinacota en los censos 1992 y 2002, nos estamos refiriendo a la suma de los datos demográficos de las comunas de Arica, Camarones, General Lagos y Putre. A su vez, cuando hablamos de Tarapacá, nos estamos refiriendo a los territorios compuestos por las comunas de Camiña, Colchane, Iquique, Pica, Pozo Almonte y Huara. ${ }^{16}$

Esta metodología de recorte supone aspectos negativos y positivos. Los aspectos negativos se refieren a que se produce la XV Región en un momento anterior a su existencia efectiva, cuestión que a su vez se refleja en la manera como presentamos las estadísticas de Tarapacá, exceptuando de esta información un contingente de población que efectivamente pertenecía a esta área administrativa tanto en 1992 como en 2002. Sin embargo, pese a estos aspectos negativos, consideramos valioso el aporte que este recorte nos ofrece para el desarrollo de los futuros desenlaces de nuestra investigación. Hay dos elementos importantes que representan los beneficios metodológicos de operar el diseño de Arica-Parinacota a partir de la agrupación de los datos poblaciones de sus actuales comunas en los censos 1992 y 2002 . El primero se refiere a que esta operación nos permite establecer un área común de comparación para las futuras muestras censales. Es decir, nos permite preparar y organizar los datos de los anteriores censos para que sean coherentes con las próximas mediciones de la población a niveles regionales. En este sentido, el análisis que aquí presentamos es un paso previo para un estudio demográfico más amplio

\footnotetext{
${ }^{16}$ Nótese que en el caso de Tarapacá, no se menciona la comuna de Alto Hospicio, fundada en 2004 , pero sí se integran las informaciones referentes a su población, puesto que en los censos de 1992 y 2002 la comuna se encontraba integrada administrativamente al territorio comunal de Iquique (sobre el proceso de creación de la comuna de Alto Hospicio, véase Guerrero-Cossio 2006).
} 
sobre la migración en el norte grande, y que se llevará a cabo tras la publicación de los datos del Censo 2012 de Chile. El segundo beneficio metodológico del recorte está en que permite conocer de manera más localizada las transformaciones que la realidad migratoria supone en el territorio de las regiones actuales, posibilitando que esta información pueda ser utilizada por las administraciones regionales en la confección de políticas públicas, o por lo menos como instrumento de acercamiento a la realidad social de sus territorios.

En relación a los criterios de selección de los datos censales analizados en el presente artículo, quisiéramos hacer hincapié en que la manera como los agrupamos fue intrínsecamente motivada por nuestras hipótesis de investigación y por las indagaciones que dan coherencia a dichos planteamientos. Todo dato cuantitativo -y especialmente los datos censales en la complejidad y variedad de informaciones que facilitan acerca de la vida y dinámicas sociales- constituye una fuente inagotable y maleable (Mitchell 2006). Queremos decir con esto que la estadística no es neutral, que su uso depende doblemente de la manera como los investigadores la acotan, sistematizan y presentan y que, de acuerdo al uso que se haga de estos "recortes", se puede llegar a argumentos muy distintos entre sí. En este sentido, es importante hacer patente que nuestras elecciones estuvieron orientadas de cara a 1) visibilizar el tipo de inserción socioeconómica y la adscripción étnica de las migrantes peruanas; 2) visibilizar las diferencias entre hombres y mujeres en el interior de cada uno de estos colectivos; y 3 ) subrayar la diferencia de esta migración femenina peruana, con aquella encontrada en el centro del país.

\section{Migración peruana en Chile: números nacionales y especificidades regionales}

Para contextualizar nuestra exposición estadística acerca de las mujeres peruanas, aportaremos una visión más amplia de su presencia en todas las regiones del territorio chileno. El dato nos permitirá inferir algunas hipótesis sobre los patrones de movilidad de esta población migrante, apuntando también hacia otros elementos de orden socioeconómico que caracterizan la diferencia de perfil migratorio entre las peruanas que se desplazan al centro y al norte del país. Como diversos autores han explicitado, la migración peruana en Chile ha crecido de manera bastante expresiva en los últimos veinte años. En el Censo 1992, los peruanos constituyan el cuarto colectivo nacional en números absolutos (con un total de 7.649 personas). La primera posición la ocupaban los migrantes argentinos (34.415 personas), seguidos de los españoles (9.849 personas), y de los bolivianos (7.729 personas) en la tercera posición. En el Censo 2002, los migrantes peruanos ya equivalían al segundo colectivo nacional más importante en Chile, totalizando 39.084 personas. La migración argentina que durante la década anterior se había incrementado considerablemente sigue su tendencia a la alza, pero de manera más moderada de lo que se observó con el colectivo peruano. El Censo 2002 también hace patente una mayor expresividad de la migración boliviana hacia Chile, y la mantención de este grupo nacional como el tercero más numeroso del país (totalizando en este año 11.649 personas). Al mismo tiempo, ganan protagonismo los migrantes ecuatorianos, ocupando la cuarta posición en números absolutos (9.762 personas).

En 2009, de acuerdo a las estimaciones del Departamento de Extranjería y Migración, Ministerio del Interior del Gobierno de Chile (DEM 2010), lo peruanos conformaban el colectivo nacional migrante más numeroso en el país, con una población de 130.959 personas, seguidos de los argentinos (60.597 personas), bolivianos (24.116 personas) y de los ecuatorianos (19.089 personas). Así, la inmigración peruana ha pasado a significar la más importante masa migrante que llega a Chile, totalizando en 2009 un número absoluto aproximadamente 17 veces mayor de lo que el colectivo significaba en 1992. Ningún otro colectivo migrante ha presentado ritmos de crecimiento comparables a los del colectivo peruano. Diferentes autores han denominado esta intensificación como una "nueva oleada migratoria peruana" (Martínez 2003: 1; Navarrete 2007: 179; Schiappacasse 2008: 23) que ha empezado su ciclo a mediados de la década de 1990 convirtiendo Chile en uno de los destinos prioritarios de la migración intrarregional sudamericana (Araujo et al. 2002: 6; Godoy 2007: 42; Núnez y Hoper 2005: 291; Núñez y Torres 2007: 7; Santander 2006: 2; Stefoni 2005: 283-284). Este período coincide con el proceso de democratización vinculado al final de la dictadura de Pinochet, cuando Chile atraviesa una fase de estabilidad política y de importante crecimiento económico (Araujo et al. 2002: 8; Erazo 2009: s/n; Jensen 


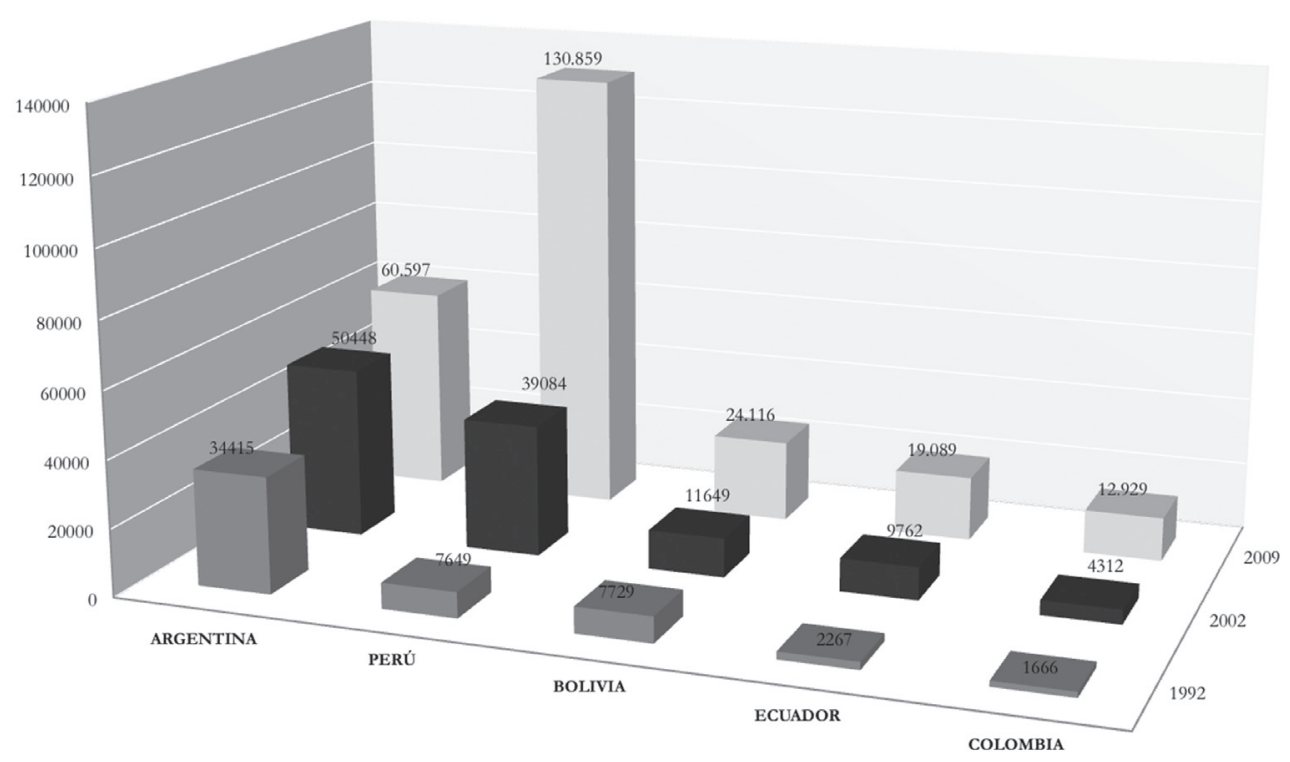

\begin{tabular}{|l|c|c|c|c|c|}
\cline { 2 - 6 } \multicolumn{1}{c|}{} & ARGENTINA & PERÚ & BOLIVIA & ECUADOR & COLOMBIA \\
\hline - 1992 & 34415 & 7649 & 7729 & 2267 & 1666 \\
\hline 2002 & 50448 & 39084 & 11649 & 9762 & 4312 \\
\hline 2009 & 60.597 & 130.859 & 24.116 & 19.089 & 12.929 \\
\hline
\end{tabular}

Figura 1. Cinco colectivos migratorios más numerosos en 2009 según el Ministerio del Interior de Chile: comparación con las informaciones censales sobre estos colectivos en 1992 y 2002 .

2009: 106; Martínez 2005: 109; Poblete 2006: 184). La emergencia del país como un posible destino migratorio a niveles regionales es simultánea a la fuerte inestabilidad económica, política y social vivida por Perú, factor que actuó condicionando un flujo migratorio peruano hacia los países limítrofes (Araujo et al. 2002: 9-10). ${ }^{17} \mathrm{La}$ Figura $1{ }^{18}$ ilustra la progresión de los cinco colectivos na-

\footnotetext{
${ }^{17}$ También es cierto que Argentina apareció como un primer destino de la migración peruana y boliviana en Latinoamérica, realidad que se mantuvo mientras la economía de este país sostuvo la paridad de cambio con el dólar, en el período anterior a la crisis del "corralito" (Lipszyc 2004: 11), determinando una importante disminución de la migración intrarregional hacia dicho país. A la vez, tras los atentados del 11 de septiembre de 2001, las restricciones de fronteras impuestas por Estados Unidos a los migrantes dificultaron sobremanera la entrada de latinoamericanos en Norteamérica (Araujo et al. 2002: 9). Si hasta 2001 Estados Unidos era el destino migratorio preferido de los peruanos, por ejemplo, a partir de esta fecha Chile y España surgen como nuevas posibilidades para el itinerario de estos migrantes andinos.

${ }^{18}$ Todas las tablas y gráficos presentados a lo largo del presente ar-
}

cionales migratorios más expresivos en Chile en 2009, comparando estos números con los que estos mismos grupos presentaban en el Censo 1992 y el Censo 2002.

Este expresivo aumento de la migración peruana en Chile, sin embargo, se distribuye de manera desigual en el territorio. No todas las regiones del país han experimentado este crecimiento del colectivo: esta es una realidad que se observa especialmente en cinco regiones -en las tres actuales regiones del Norte Grande (Arica-Parinacota, Tarapacá y Antofagasta) y en dos regiones ubicadas en el territorio central del país (Santiago y Valparaíso).

\footnotetext{
tículo fueron producidos a partir de la información publicada por el INE-Chile, procesada por el sistema Redatam. Los datos que aquí usamos pueden ser consultados en: http://www.ine.cl/. Los datos referentes a los migrantes internacionales en Chile para el año 2009 fueron retirados del Informe Anual del Departamento de Extranjería y Migración - Ministerio del Interior del Gobierno de Chile. Este informe no permite la comparación con los datos regionales, puesto que publica estadísticas totales nacionales.
} 


\begin{tabular}{|c|c|c|c|}
\hline Región & Hombre & Mujer & Total \\
\hline Santiago & 11783 & 18445 & 30228 \\
\hline Tarapacá & 2081 & 2831 & 4912 \\
\hline Valparaíso & 519 & 652 & 1171 \\
\hline Antofagasta & 425 & 543 & 968 \\
\hline Coquimbo & 172 & 215 & 387 \\
\hline Biobío & 168 & 183 & 351 \\
\hline O'Higgins & 108 & 160 & 268 \\
\hline Atacama & 89 & 122 & 211 \\
\hline Maule & 89 & 116 & 205 \\
\hline Los Lagos & 87 & 108 & 195 \\
\hline La Araucanía & 63 & 70 & 133 \\
\hline $\begin{array}{l}\text { Magallanes y } \\
\text { Antártida }\end{array}$ & 14 & 16 & 30 \\
\hline Aysén & 14 & 11 & 25 \\
\hline
\end{tabular}

Tabla 1. Migración peruana según sexo: división regional. Censo 2002, Chile ${ }^{1}$

\footnotetext{
${ }^{1}$ En esta tabla, los datos referentes a las regiones de Arica-Parinacota y Tarapacá aparecen agrupados en los números de esta segunda región. En las demás Tablas y Figuras, conforme explicamos al inicio de este apartado, presentaremos las dos regiones separadas a partir del recorte de sus actuales comunas.
}

La Tabla 1 ordena de modo descendente las regiones con mayor presencia de migrantes peruanos en números absolutos. En este sentido, las cuatro primeras regiones serían la de Santiago, Tarapacá, Valparaíso y Antofagasta. No obstante, la diferencia en números absolutos entre las concentraciones migratorias de estas regiones y las de la región Metropolitana es bastante expresiva. Sobre este punto, habría que considerar que Santiago es la región más poblada de Chile, y que en términos relativos la capital no necesariamente representa el área donde los migrantes peruanos son proporcionalmente más numerosos. Así, si analizamos los datos del Censo 2002 sobre el número de migrantes peruanos en el entonces territorio de Tarapacá (4.912 personas) en relación al número total de habitantes de la región (428.594 personas), tenemos que estos migrantes representan un 1,15\% de la población. Para el mismo año, lo peruanos significaban un $0,5 \%$ de la población santiaguina total. Este dato es importante porque desarticula el argumento acerca del señalamiento de Santiago como la región nacional donde la migración peruana se hace "excepcionalmente" presente y voluminosa. La estadística nos ayuda a entender que el recorte geográfico del área de Santiago como locus sine qua non del estudio sobre migrantes peruanos en Chile se debe a lógicas de localización de otro orden: que no se vinculan necesariamente a la importancia numérica o proporcional del fenómeno. Así, la casi inexistencia de estudios sobre el fenómeno migratorio actualmente registrado en las regiones del norte, al modo de lo que ocurre con la región de Valparaíso, ${ }^{19}$ dice relación antes con una distorsión de la mirada geográfica hacia el fenómeno, que con su supuesta inexistencia en estas regiones.

Es dable suponer que la realidad migratoria de los peruanos -desde los motivos que impulsan su proyecto migratorio, pasando por el tipo de capital que acumulan para financiar su desplazamiento, los vínculos comunitarios (nacionales o transnacionales) que activan al migrar, y las lógicas de movilidad en territorio chileno- son circunstancialmente diferentes según el destino de estos migrantes sea el centro o el norte de Chile. Pero nos parece inadecuado suponer que se tratan de dos modelos homogéneos y en oposición. No hay una sola migración femenina peruana al norte, de

${ }^{19}$ La región de Valparaíso, en el centro del país, con su importante papel como principal puerto internacional chileno, viene siendo un escenario de acogida de migrantes internacionales muy expresivo desde inicios del siglo XIX -lo que en gran medida ha ayudado a dar forma a los aspectos culturales, sociales y económicos de la vida cotidiana en esta región. Actualmente, Valparaíso cuenta con una expresiva migración latinoamericana (en la que se incluye el colectivo peruano residente en su mayoría en las comunas de Valparaíso, Viña del Mar, Quillota y Villa Alemana). Este fenómeno, sin embargo, ha pasado desapercibido por los investigadores que estudian el tema en Santiago. 
la misma manera que no hay una sola migración femenina peruana al centro. Sin realizar trabajo de campo cualitativo, no podemos afirmar que los perfiles, itinerarios y condiciones de inserción social de las mujeres peruanas en Santiago y Valparaíso sean similares, pese a que exista una conexión activa entre las comunidades peruanas en estas dos áreas centrales de Chile. La misma precaución debiéramos asumir evitando anunciar una supuesta homogeneidad en los perfiles y experiencias de las peruanas en las tres regiones que componen el Norte Grande.

Desde el ya clásico estudio de Mujica (2004), muchos autores han afirmado que los migrantes peruanos en Santiago provienen preferentemente del norte de Perú, especialmente de Trujillo, Chiclayo y Chimbote. ${ }^{20}$ Este no es el caso para la migración peruana en el norte chileno. Aunque todavía no existan estudios conclusivos sobre estas regiones, nuestra observación participante de ciudades norteñas como Arica, Iquique, Antofagasta y Calama nos permite afirmar que las mujeres peruanas desplazadas hacia estas localidades chilenas provienen de territorios del sur peruano, y que su elección de migrar hacia estas comunas se debe en gran medida a la posibilidad de volver más a menudo a sus ciudades de origen en Perú. Esto determina que sus estrategias de desplazamiento sean diferentes de las que realizan las peruanas que viven en la región Metropolitana, y que además estén marcadas por circuitos de movilidad más intensos, con más viajes entre los dos países -lo que en última instancia determina condiciones sui generis para el transnacionalismo vivido y activado por estas migrantes. ${ }^{21}$ Muchas

\footnotetext{
${ }^{20}$ Gran parte de los autores han tendido a afirmar que toda la migración peruana en Chile provendría de estas ciudades, pero en ningún caso se cuestiona alguna variabilidad regional al respecto. En otras palabras, nadie ha preguntado a las peruanas en el norte y en el sur de Chile de donde provienen: esta es una pregunta que se ha hecho solamente a los y las peruanas de la región Metropolitana chilena. Véase este mismo proceso de generalización en: Godoy (2004: 46), Santander (2006: 10). Poblete es un ejemplo interesante en este sentido, pues reproduce en su texto la idea de que los migrantes peruanos "en Chile" provienen mayoritariamente de Trujillo y Chimbote (2006: 205) y, páginas después, desglosa el dato citando que la información fue originalmente recopilada por Mujica (2004) en su estudio realizado exclusivamente en la ciudad de Santiago (Poblete 2006: 207).

${ }^{21}$ Si en Santiago las migrantes hacen uso de empresas internacionales de envío de dinero para hacer llegar las remesas a sus familias en Perú (Stefoni 2005), en el norte la circulación del dinero
}

de las peruanas que trabajan en Arica-localidad chilena ubicada a tan solamente 58 kilómetros de Tacna, la ciudad peruana más próxima- viven en Chile solamente los días de semana, devolviéndose a sus casas en Perú los fines de semana. Otras peruanas optan por ir a diario a Chile, lo que construye una interesante relación con el eje transfronterizo acotando los espacios de trabajo al territorio chileno, a la vez que se acota la vivienda al Perú. Esto determina otro patrón de transferencia del capital recibido por el trabajo, en la medida en que gran parte de este capital se gastará en origen, movilizando de manera más intensa las economías locales en las ciudades peruanas de donde provienen estas migrantes. Esta es una realidad que remonta directamente a la especificidad de la zona de frontera. ${ }^{22}$ No podemos comprender estas

está a cargo de las mismas mujeres que lo llevan personalmente a sus familias. Esto implica una relación diferente de estas migrantes con su nueva figura de mantenedoras económicas: una relación más directa, más presencial de lo que ocurre con las peruanas en Santiago.

${ }^{22}$ Como afirma Garduño, la conceptualización de las fronteras como locus de formas y campos sociales sui generis ha cambiado fuertemente en las ciencias sociales en los últimos 30 años: "Tradicionalmente, la perspectiva que ha prevalecido como hegemónica es la que ha asumido a las fronteras, en su sentido literal, como regiones geográficas en las que se expresan una serie de problemas sociales y económicos concretos, relacionados con las poblaciones aborígenes, la migración, las implicaciones del paulatino crecimiento de la industria maquiladora y las políticas fronterizas adoptadas por los respectivos Estados, incluyendo los tratados binacionales (González 1981). Frente a esta perspectiva literal, sin embargo, se ha erigido la perspectiva aliteral, que da mayor importancia a los estudios culturales. Como pioneros de esta última podemos mencionar los trabajos realizados desde un determinado enfoque que bien puede denominarse transcultural y que visualizaba a las poblaciones fronterizas como conjuntos de individuos con dudosas lealtades hacia el centro y en proceso de pérdida de los vínculos que los unían a sus respectivas culturas madre (Nostrand 1983: 11 y Meggers 1954, citados en Kutsche 1983). Posteriormente, y en reacción a esta perspectiva, es elaborado un discurso que viene a denunciar a la perspectiva transcultural como una expresión de la miopía opresiva del centro, que ignoraba la fuerte identidad nacional de los fronterizos (Friedmann et al. 1985: 34-35)". Sea como fuera, las regiones de frontera se constituyen como espacios donde los sentidos de pertenencia identitaria y espacial son diariamente re-configurados y tensionados a raíz de la fuerte experiencia de movilidad humana que caracteriza estas áreas. De esta manera, asumimos que la región fronteriza se constituye como espacio con unas dinámicas migratorias y sociales propias que difieren circunstancialmente de territorios otros. 
estrategias de las migrantes peruanas en el norte sin considerar que este tipo de flujo Perú-Chile-Perú es parte de los paisajes locales, es parte de lo que define la estructura económica, social y política de ciudades como Arica y Tacna, entre las cuales se registra un flujo humano diario de entre 7 mil y 10 mil personas.

Lo que también resulta fundamental a la hora de diferenciar los rasgos generales de esta migración femenina peruana en territorios del norte de Chile de la migración peruana en el centro del país se refiere justamente a las especificidades documentales que la realidad fronteriza condiciona. En la zona de frontera los peruanos pueden circular en territorios chilenos durante una semana sin que se les requiera ninguna documentación (visados, permisos especiales, etc.). A consecuencia de ello, muchas de las mujeres que optan por vivir entre Perú y Chile trabajan de manera ilegal. Muchas de ellas nunca llegan a gestionar un pedido de visa de trabajo, razón por la cual no existen formalmente para el Gobierno de Chile. Esto implica que estas mujeres no puedan contribuir al sistema de salud pública, o al sistema de previsión social, estando por lo tanto expuestas a un tipo de marginalidad social-jurídica y política que determina la denegación de su ciudadanía en Chile y que, lógicamente, permite patrones de abuso laboral bastante intensos. Pese a que esta sea una realidad que también se observa en Santiago, hemos constatado en nuestras observaciones participantes en el norte, sobre todo en Arica, que este "nivel de informalidad" y de "precarización laboral" de las peruanas en la frontera es más intenso de lo que se ha observado en el centro del país, y esto se debe justamente a la especificidad de la condición fronteriza. En Santiago, esquivar la condición de ilegalidad documental es una tarea compleja en la medida en que las migrante no pueden recurrir con la misma facilidad al cruce de fronteras. Las peruanas en el norte tienen más sencillo devolverse a un territorio nacional donde son efectivamente ciudadanas, lo que les permite soportar por más tiempo la informalidad jurídica en Chile.

Aun en relación a las especificidades de las migrantes peruanas en el norte, hemos observado otro aspecto referente a su estrategia de movilidad que les conforma características diferentes de las que encontramos en las peruanas emigradas a Santiago. Esta diferencia se refiere a que estas mujeres provienen de regiones en Perú que se han constituido como emisoras de migración interna hacia la capital, Lima. ${ }^{23}$ Algunas de estas mujeres nos decían que miembros de sus familias se desplazaron hacia Lima para buscar trabajo en los años setenta y ochenta. Sin embargo, ahora que las ciudades fronterizas chilenas permiten un mismo nivel salarial que lo que se ofrece en Lima por trabajos domésticos, les resulta mejor, más rápido y menos cansador emigrar a Chile. Arica, en este sentido, se ha convertido en una nueva alternativa migratoria. Así, esta emergencia de las ciudades del norte de Chile como espacios de "desarrollo económico" condiciona una reorganización de la experiencia migrante de algunas familias peruanas. Estas familias emplean sus experiencias, imaginarios y prácticas migrantes del pasado siglo - consolidadas como prácticas internas en Perúadaptando estos saberes a una práctica transnacional.

\section{La feminización de las migraciones peruanas. Datos comparativos entre Santiago y el Norte Grande: educación, acceso al mercado laboral, vinculación étnica}

Otro dado fundamental sobre la inmigración reciente en Chile se refiere justamente al proceso de feminización de los desplazamientos de población proveniente de países del contexto intrarregional latinoamericano. En 1992, prácticamente todos los colectivos migrantes latinoamericanos en Chile (entre ellos el argentino, peruano, boliviano, ecuatoriano, brasileño y colombiano) se caracterizaban por presentar una muy incipiente -casi inexpresiva a niveles estadísticos- mayoría femenina. En dicho año, hombres y mujeres de estos colectivos tenían un nivel de participación muy cercano al 50\% en relación al total del grupo. En 2002, la tendencia a feminización

\footnotetext{
${ }^{23}$ Perú sufrió un intenso proceso de desplazamiento campo-ciudad en el marco de la transición urbana del país y que resultó en el crecimiento abrupto de la capital Lima (Golte y Adams 1990). Poblaciones rurales de todo el país migraron hacia la capital y esto es cierto no solamente para las ciudades del norte de Perú, sino también para aquellas que están situadas en el sur, en la frontera con Chile. Estas migraciones internas han dado paso a la consolidación de redes migrantes que han actuado potenciando el éxodo rural especialmente entre 1960 y 1980. Como bien explicita Annelou Ypeij (2000), esta migración interna resultó en un proceso de inserción de las mujeres en la economía informal de la capital Lima, teniendo por ende unas consecuencias particulares al condicionamiento de la precariedad laboral de las mujeres.
} 


\begin{tabular}{|c|c|c|c|c|c|c|}
\hline \multirow{2}{*}{ Nacionalidad } & \multicolumn{2}{|c|}{1992} & \multicolumn{2}{|c|}{2002} & \multicolumn{2}{|c|}{2009} \\
\hline & Hombres & Mujeres & Hombres & Mujeres & Hombres & Mujeres \\
\hline ARGENTINA & 16930 & 17485 & 25475 & 24973 & 30517 & 30080 \\
\hline PERÚ & 3869 & 3780 & 15612 & 23472 & 56545 & 74314 \\
\hline BOLIVIA & 3679 & 4050 & 5433 & 6216 & 11122 & 12994 \\
\hline ECUADOR & 1061 & 1206 & 4415 & 5347 & 8585 & 10504 \\
\hline ESPAÑA & 5225 & 4624 & 4990 & 4541 & 5833 & 5192 \\
\hline BRASIL & 2165 & 2445 & 3631 & 3958 & 4339 & 5285 \\
\hline EEUU & 3388 & 2861 & 4866 & 3824 & 5322 & 4398 \\
\hline ALEMANIA & 2231 & 2341 & 2946 & 2960 & 3284 & 3263 \\
\hline COLOMBIA & 736 & 930 & 1961 & 2351 & 5370 & 7559 \\
\hline CHINA & 476 & 312 & 986 & 742 & 2353 & 2236 \\
\hline
\end{tabular}

Tabla 2. Extranjeros en Chile Según sexo. Números absolutos para todas las regiones nacionales. Censo 1992 y 2002 e Informe Anual 2010 - Departamento de Extranjería y Migración de Chile. ${ }^{1}$

1 Todas las tablas que presentamos en el presente texto son de elaboración propia a partir de los datos del XVII Censo Nacional de Población y VI de Vivienda 2002. CELADE, División de Población de la CEPAL 2002-2006; y de los datos del Informe Anual 2010, Departamento de Extranjería y Migración de Chile Ministerio del Interior.

empieza a presentarse de manera más marcada: a excepción del colectivo argentino, todos los demás contaban con un número de mujeres superior al número de hombres. En 2009 la feminización ya se había convertido en un hecho y las mujeres aparecían muy claramente como mayorías absolutas en casi todos los grupos migrantes provenientes de otros países de América Latina. En este año, según las estimativas del Departamento de Extranjería de Chile, las peruanas correspondían al 57\% del total de migrantes de su país, las bolivianas al 54\%; las ecuatorianas al $55 \%$; las colombianas al $58,5 \%$ y las brasileñas al $55 \%$. Las argentinas seguían siendo una excepción a esta regla, constituyendo la mitad del total (aproximadamente un 49,6\%) de los migrantes de su misma nacionalidad en Chile. ${ }^{24}$ La Tabla 2 ilustra los nú-

\footnotetext{
${ }^{24}$ Acosta (2011: 218), utilizando los datos de la encuesta de Caracterización Socioeconómica Nacional (CASEN 2006), llevada a cabo por el Ministerio de Desarrollo Social del Gobierno de Chile, aporta índices de feminización divergentes de los que aquí presentamos. Según la autora, para el año 2006 (en que se realizó la última
}

meros absolutos de mujeres en los colectivos migrantes más numerosos en Chile para el año 2009, comparando esta información con los valores que estos colectivos presentaban en 1992 y 2002.

Lo que nos interesa aquí, sin embargo, es que esta característica -la feminización de los grupos migrantes latinoamericanos- que observamos como una tendencia a niveles nacionales en Chile, presenta importantes matices de carácter regional. En lo que se refiere al colectivo peruano, del que aquí nos ocupamos, esta tendencia a la feminización es muy acentuada tanto en las tres actuales regiones del Norte Grande, como en Santiago y se constituye para todas estas áreas como un rasgo definitorio del colectivo como un todo. La Tabla 3 aporta el número total de migrantes peruanos según sexo en las tres regiones nortinas y en Santiago, dando cuenta

encuesta CASEN), las mujeres corresponderían al 56,4\% del total de migrantes de nacionalidad argentina; el $57,8 \%$ en el colectivo peruano; el $57 \%$ en el boliviano y el $49 \%$ en el ecuatoriano. 


\begin{tabular}{|c|c|c|c|c|}
\hline \multicolumn{5}{|c|}{ Migrantes peruanos según sexo } \\
\hline \multicolumn{5}{|c|}{ Censo 1992-2002 (Frecuencias absolutas) } \\
\hline \multirow{3}{*}{ REGIÓN } & \multicolumn{4}{|c|}{ Sexo del encuestado } \\
\hline & \multicolumn{2}{|c|}{ Hombre } & \multicolumn{2}{|c|}{ Mujer } \\
\hline & 1992 & 2002 & 1992 & 2002 \\
\hline Arica-Parinacota & 629 & 939 & 626 & 1240 \\
\hline Tarapacá & 222 & 1091 & 148 & 1551 \\
\hline Antofagasta & 99 & 412 & 105 & 531 \\
\hline Santiago & 2266 & 11783 & 2298 & 18445 \\
\hline
\end{tabular}

Tabla 3. Migrantes peruanos según sexo en Arica-Parinacota, Tarapacá, Antofagasta y Santiago. Censos 1992 y 2002.

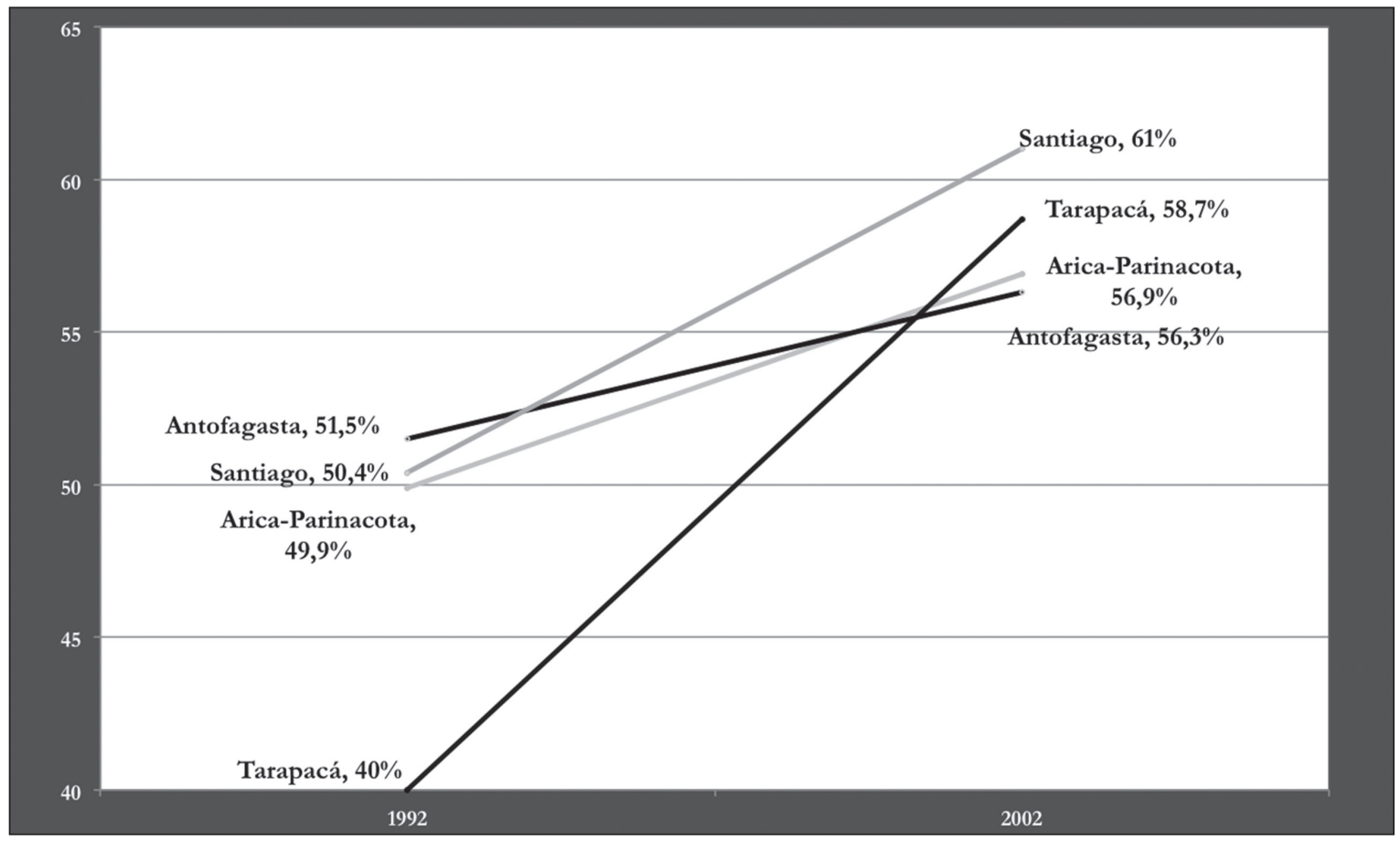

Figura 2. Porcentaje de mujeres en relación al total de migrantes peruanos: regiones de Arica-Parinacota, Tarapacá, Antofagasta y Santiago. Censo 1992 y Censo 2002.

de las diferencias en la progresión de la proporción de las mujeres en relación al total de colectivo en cada una de estas regiones entre 1992 y 2002 . La Figura 2 ilustra este mismo dato pero considerando la información porcentual de la participación femenina en el colectivo peruano en relación al total de migrantes de esta nacionalidad para estas cuatro regiones.

Como observamos, esta feminización del colectivo ha tendido a ser muy relevante para las cuatro regiones 


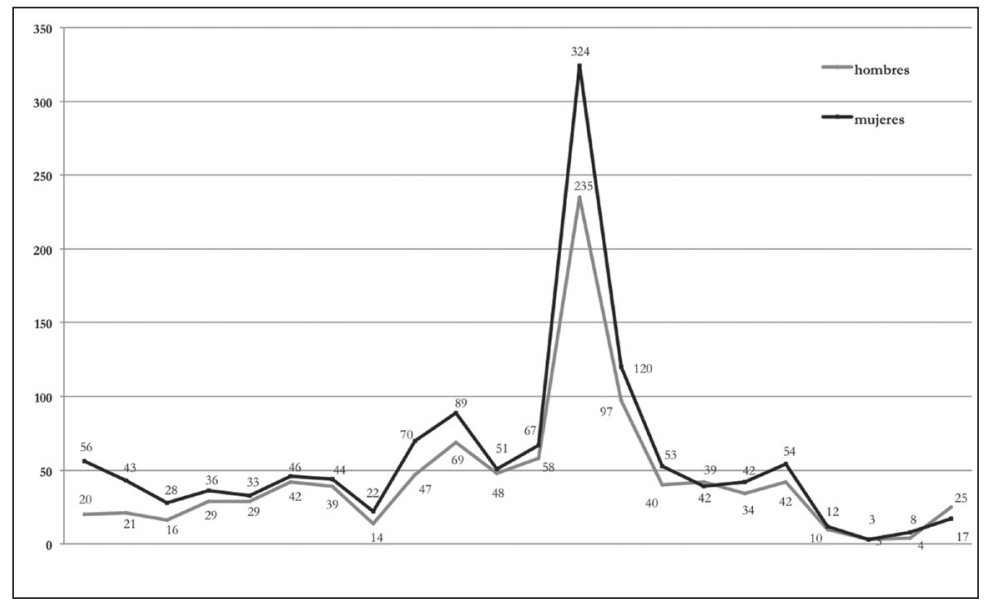

Figura 3. Número de años de estudio de los migrantes peruanos en la actual región de Arica-Parinacota (comunas de Arica, Camarones, General Lagos). Censo 2002.

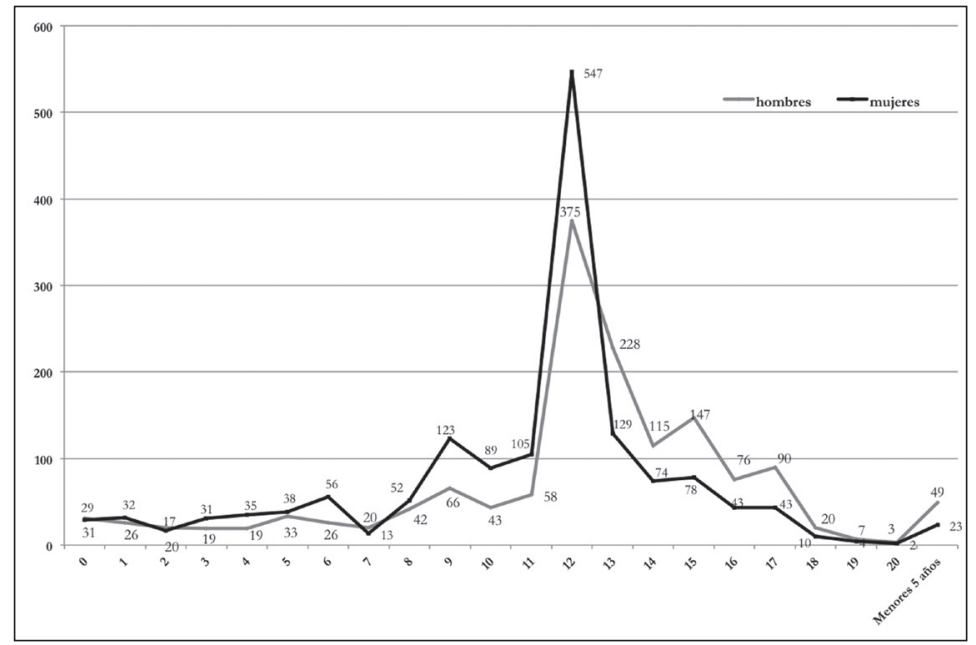

Figura 4. Número de años de estudio de los migrantes peruanos en la actual región de Tarapacá (comunas de Iquique, Camiña, Pica, Pozo Almonte, Huara y Colchane) Censo 2002.

analizadas: en Santiago, las mujeres peruanas incrementaron su participación sobre el total de migrantes de su misma nacionalidad en un 10,6\% entre 1992 y 2002 (pasando de 50,4\% a 61\% del total de peruanos). Si por un lado es cierto que Santiago constituye el locus donde las peruanas eran más numerosas en 2002 en términos absolutos ( 18.445 personas) y en términos proporcionales (el 61\% del total de los migrantes peruanos), también es cierto que las regiones del norte presentaron una feminización igualmente importan- te, y en algunos casos más acentuada que la que verificamos en la región Metropolitana. En Tarapacá por ejemplo, las peruanas pasaron de componer un 40\% del total de peruanos en la región en 1992, a componer un $58,7 \%$ en 2002: un incremento del orden del $18,7 \%$, muy superior al ritmo de feminización que observamos en la capital. Arica-Parinacota y Antofagasta también presentan aumentos significativos de la población peruana femenina, la primera región con un incremento de la participación de las mujeres en un 7\% entre 1992 


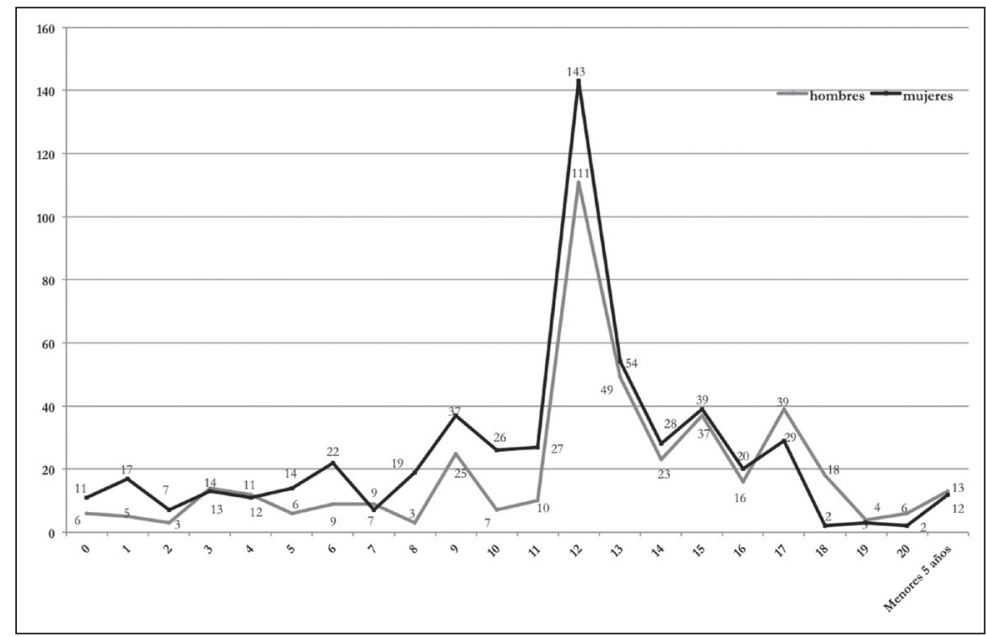

Figura 5. Número de años de estudio de los migrantes peruanos en la región de Antofagasta. Censo 2002.

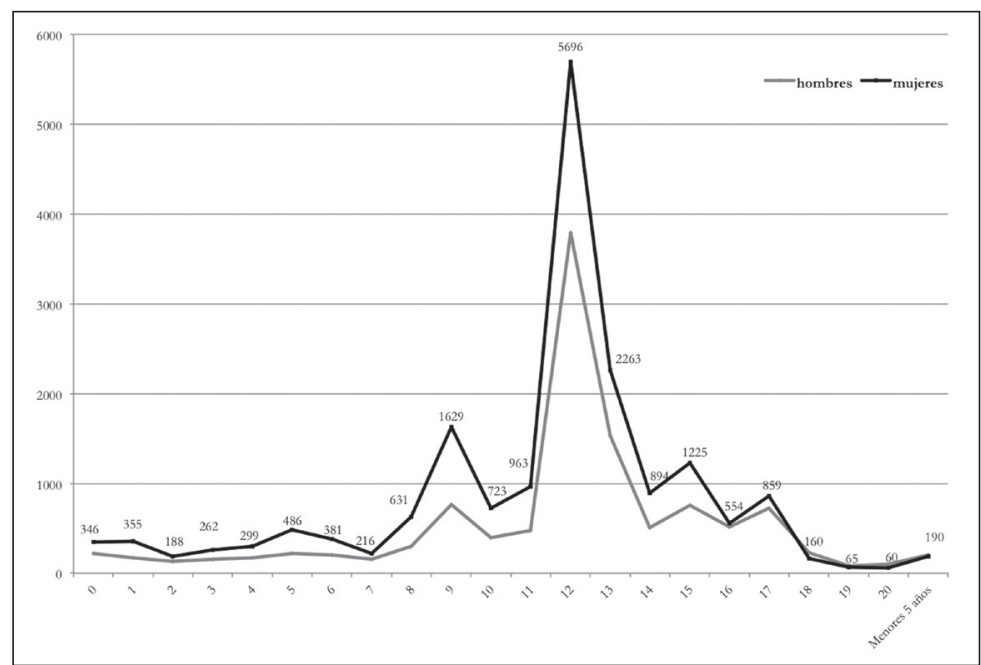

Figura 6. Número de años de estudio de los migrantes peruanos en la región Metropolitana. Censo 2002.

y 2002, y la segunda con un incremento del 4,8\% en el mismo período.

Llama la atención el hecho de que estas migrantes peruanas tengan una media de acceso a la educación formal superior a la media nacional chilena: la mayor parte de ellas ha completado un total de 12 años de educación formal, lo que es cierto tanto para las tres regiones del norte de Chile, como también para la región metropolitana. Considerando que la mayor parte de estas mujeres trabaja en los servicios domésticos y de cuidado, se puede decir que su nivel de escolarización es superior a la media de las trabajadoras chilenas dedicadas a la misma función -que accede a los ocho años de escolarización formal (Stefoni 2009). Las Figuras 3-6 ilustran los años de estudio de las mujeres peruanas para Arica-Parinacota, Tarapacá, Antofagasta y para la región Metropolitana según el Censo 2002. Se observa una curva semejante en el gráfico de estas cuatro regiones, apuntando a un perfil parecido de escolarización de las peruanas tanto en el centro como 
Menara Lube Guizardi, Alejandro Garcés H.

\begin{tabular}{|c|c|c|c|c|c|c|c|c|c|c|c|}
\hline Región & & $\begin{array}{c}\text { Alacalufe } \\
\text { (Kawashkar) }\end{array}$ & Atacameño & Aymara & Colla & Mapuche & Quechua & Rapanui & $\begin{array}{l}\text { Yámana } \\
\text { (Yagán) }\end{array}$ & NRA & Total \\
\hline $\begin{array}{c}\text { Arica- } \\
\text { Parinacota }\end{array}$ & hombre & O & $\mathrm{O}$ & 187 & 1 & 3 & 46 & o & o & 727 & 964 \\
\hline $\begin{array}{c}\text { Arica- } \\
\text { Parinacota }\end{array}$ & mujeres & o & 1 & 262 & o & 2 & 58 & o & ० & 934 & 1257 \\
\hline Tarapacá & hombres & 1 & 1 & 22 & 1 & 1 & 43 & o & ○ & 1048 & 1117 \\
\hline Tarapacá & mujeres & o & o & 48 & 1 & o & 49 & o & 1 & 1170 & 1573 \\
\hline Antofagasta & hombres & o & o & 6 & o & o & 9 & o & o & 410 & 425 \\
\hline Antofagasta & mujeres & o & o & 9 & o & o & 8 & o & o & 526 & 543 \\
\hline Santiago & hombres & o & 3 & 56 & 1 & 7 & 311 & 2 & 2 & 11401 & 11783 \\
\hline Santiago & mujeres & o & 5 & 112 & o & 6 & 439 & 2 & 5 & 17876 & 18445 \\
\hline
\end{tabular}

Tabla 4. Personas de origen peruano que declaran pertenencia o vinculación a pueblo indígena y/o originario, según sexo. Regiones de Tarapacá, Antofagasta y Santiago, Censo 2002

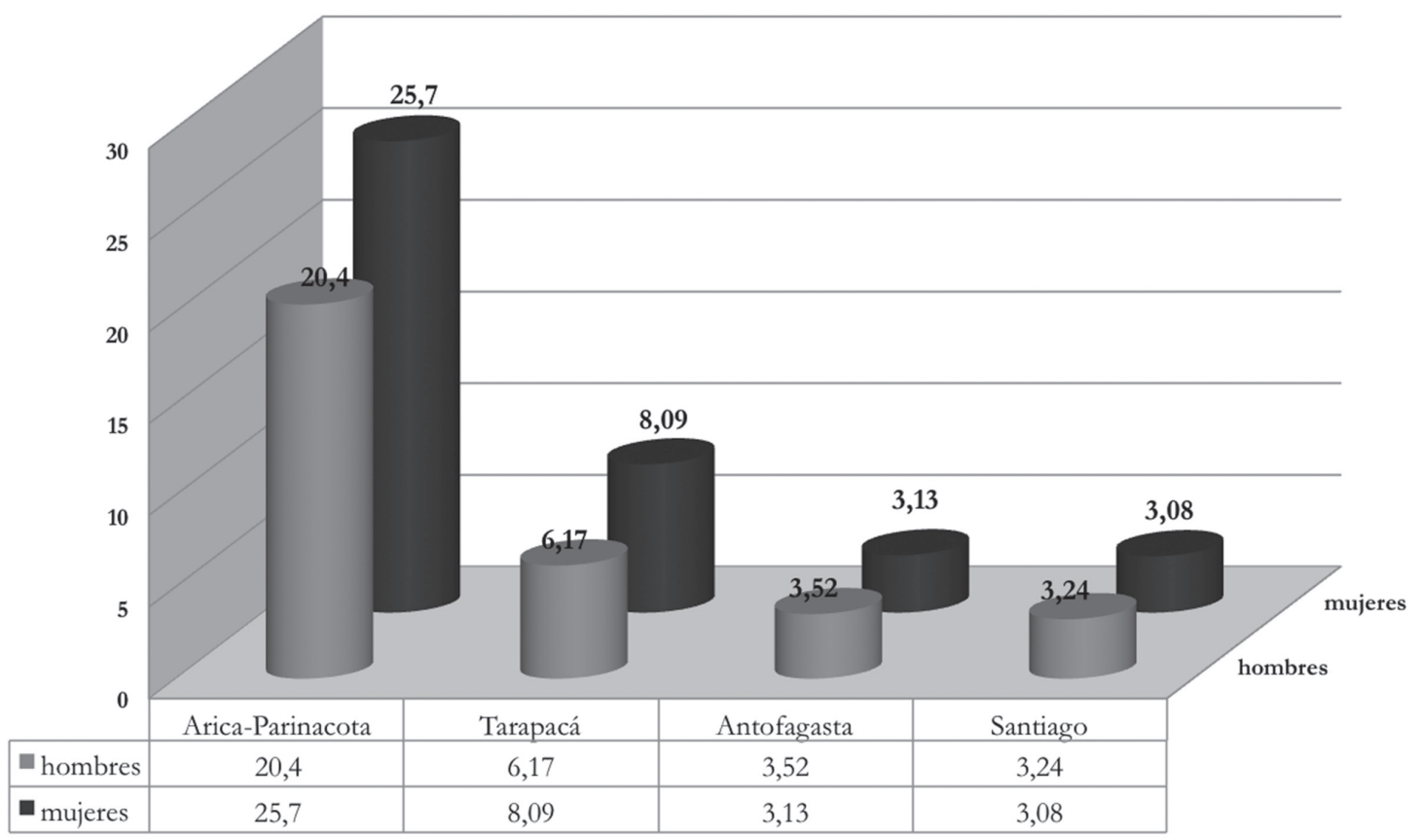

Figura 7. Porcentaje de mujeres peruanas que declaran pertenencia o vinculación a pueblo indígena y/o originario; regiones de Tarapacá, Antofagasta y Santiago, Censo 2002. 
en el norte de Chile. La excepción aparece en la región de Antofagasta, donde observamos que los hombres con más escolaridad son más numerosos que las mujeres, lo que puede indicar un nicho laboral masculino en esta región - probablemente debido a la necesidad de mano de obra masculina cualificada en la industria minera de ciudades como Calama y Antofagasta.

Pese a que encontremos semejanza entre los perfiles educacionales de las peruanas que migran al norte de Chile y aquellas que migran al centro del país, hay características de otro orden que diferencian a estas mujeres. Cuando en el Censo 2002 fueron consultadas sobre su pertenencia a pueblos originarios o grupos étnicos/indígenas, la gran mayoría de las migrantes peruanas declaró no estar vinculadas a ninguna de las ocho etnias incluidas en la encuesta (alacalufe, atacameño, aymara, kolla, quechua, mapuche, rapanui, yámana). En todo caso, entre hombres y mujeres, las segundas fueron las que más explicitaron vinculaciones étnicas, sea en las regiones del norte de Chile, sea en el centro del país, y la gran mayoría declaró pertenecer a grupos aymaras y quechuas, una regularidad que se verifica en las cuatro regiones que aquí analizamos (véase Tabla 4).

Lo que diferencia las mujeres peruanas emigradas al norte está en que-pese a que la mayoría no declare pertenencia étnica y que, al igual en la región Metropolitana, las que sí declaran son aymaras y quechuas- la concentración de mujeres peruanas con alguna vinculación indígena es expresivamente más relevante en tierras más cercanas a la frontera con Perú. Notamos pues una importante característica que correlaciona las regiones fronterizas con un cierto perfil étnico de las migrantes mujeres provenientes de territorios peruanos. En Arica-Parinacota, región chilena que colinda con Perú, un 25,7\% de las peruanas declararon ser indígenas. En Tarapacá, región inmediatamente al sur de Arica-Parinacota, un 8,09\% de las peruanas se reconocieron como indígenas. Más al sur aún, en la región de Antofagasta, un 3,13\% afirmarían su pertenencia a grupos étnicos, mientras en el centro de Chile, en la región Metropolitana solamente un 3,08\% de las mujeres lo haría (véase Figura 7). En este sentido, la etnicidad de las mujeres peruanas en el norte de Chile se constituye como un fenómeno relevante para su experiencia migrante, incidiendo en sus proceso de inserción en el mercado laboral y en el conjunto amplio de sus rela- ciones sociales: las barreras y adscripciones relacionales que sobre ellas pesan no serán homogéneamente las mismas que encuentran en la capital de Chile las migrantes peruanas. No queremos con esto caer en el esencialismo de afirmar que hay un contenido ancestral indígena que define y/o determina la manera cómo viven las peruanas en el Norte Grande. Lo que nos parece relevante, más allá de estos esencialismos, es la necesidad de indagar en cómo este diferencial de etnicidad opera a la hora de permitir/impedir, facilitar/dificultar la inserción social y económica de estas poblaciones. Y, sobre todo, los despliegues de esta etnicidad en relación con la operación de mitologías sobre pertenencia y exclusión en los imaginarios nacionalistas chilenos que actúan desigualmente en el centro y norte del país. Este constituiría unos de los temas centrales a abordar en estudios cualitativos sobre la migración en el norte de Chile.

Finalmente, hay un dato censal acerca de la inserción laboral de las migrantes peruanas en el norte chileno que construye una nueva particularidad del fenómeno. Para las regiones de Arica-Parinacota, Tarapacá, Antofagasta y también para la región Metropolitana, el Censo 2002 nos informa que la categoría laboral que congrega un mayor número de peruanas es la que se denomina "trabajadoras por ingreso" (véase Figuras 8-11). Esta es la categoría en la que se adscriben un mayor número de peruanas (12.004 en la región Metropolitana; 475 en Arica-Parinacota; 801 en Tarapacá; y 237 en Antofagasta). Se confirma así una tendencia transversal en estas cuatro regiones, relacionada a la existencia de una demanda por servicios del cuidado y del trabajo doméstico en las diferentes localidades chilenas - mercado que permite la incorporación de las peruanas como trabajadoras por ingreso, prestando servicios relacionados a la reproducción social de las familias chilenas. Sin embargo, cuando miramos los gráficos sobre la inserción laboral de las peruanas en el norte, una segunda categoría aparece de manera muy significativa, ocupando un lugar expresivo que no encuentra símil en el caso de la región Metropolitana. Esta categoría laboral se refiere a las mujeres que trabajan en "quehaceres de su propio hogar". En Arica-Parinacota, por ejemplo, el Censo 2002 registró un total de 325 peruanas trabajando en su hogar, contra 475 trabajando por ingresos. En Tarapacá la proporción es menos significativa, pero igualmente relevante: un total de 400 peruanas trabajando en su hogar, contra 801 trabajando por ingresos. En Antofagasta 


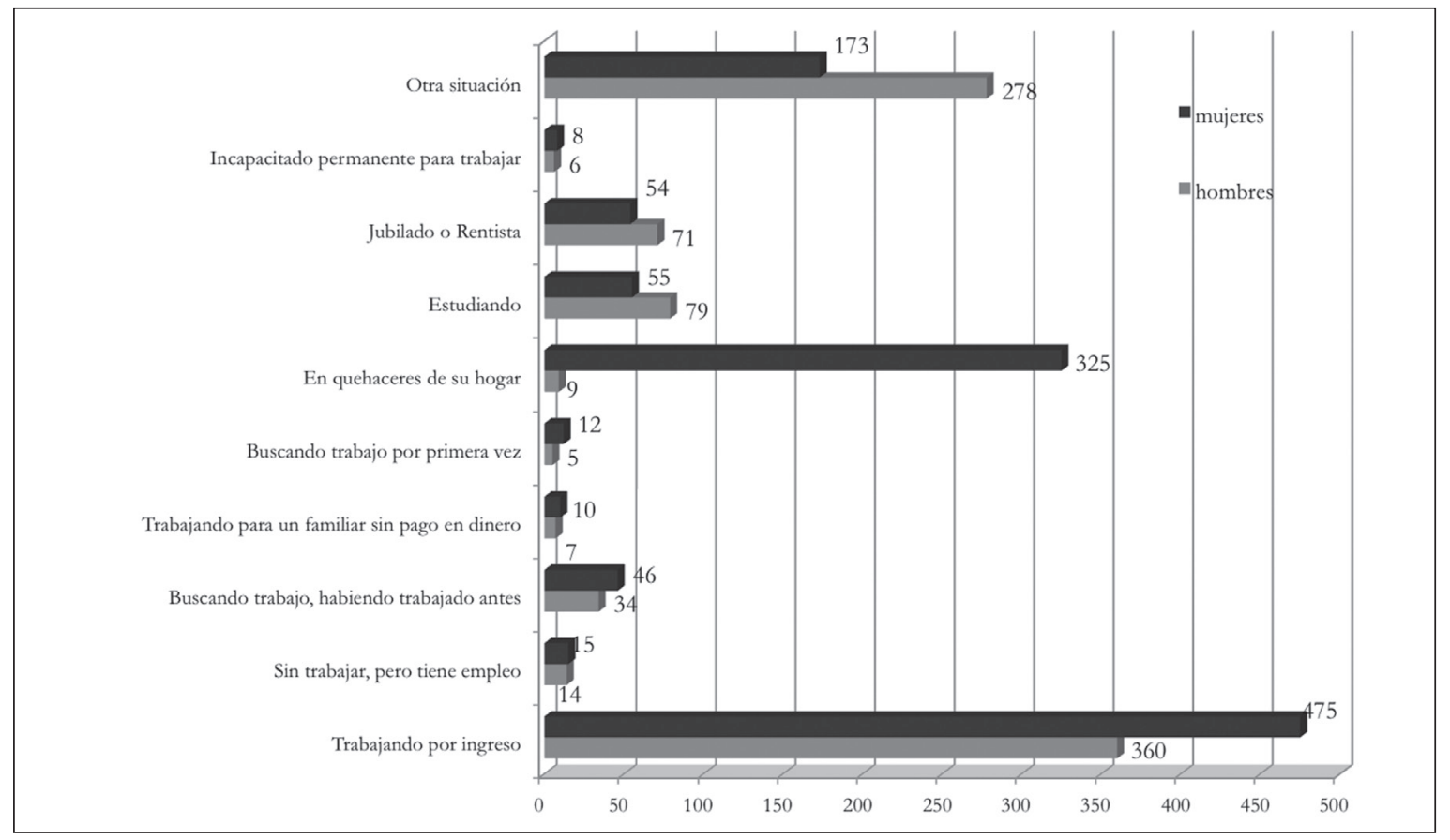

Figura 8. Situación laboral de los migrantes peruanos en la actual región de Arica-Parinacota (comunas de Arica, Camarones, General Lagos). Censo 2002.

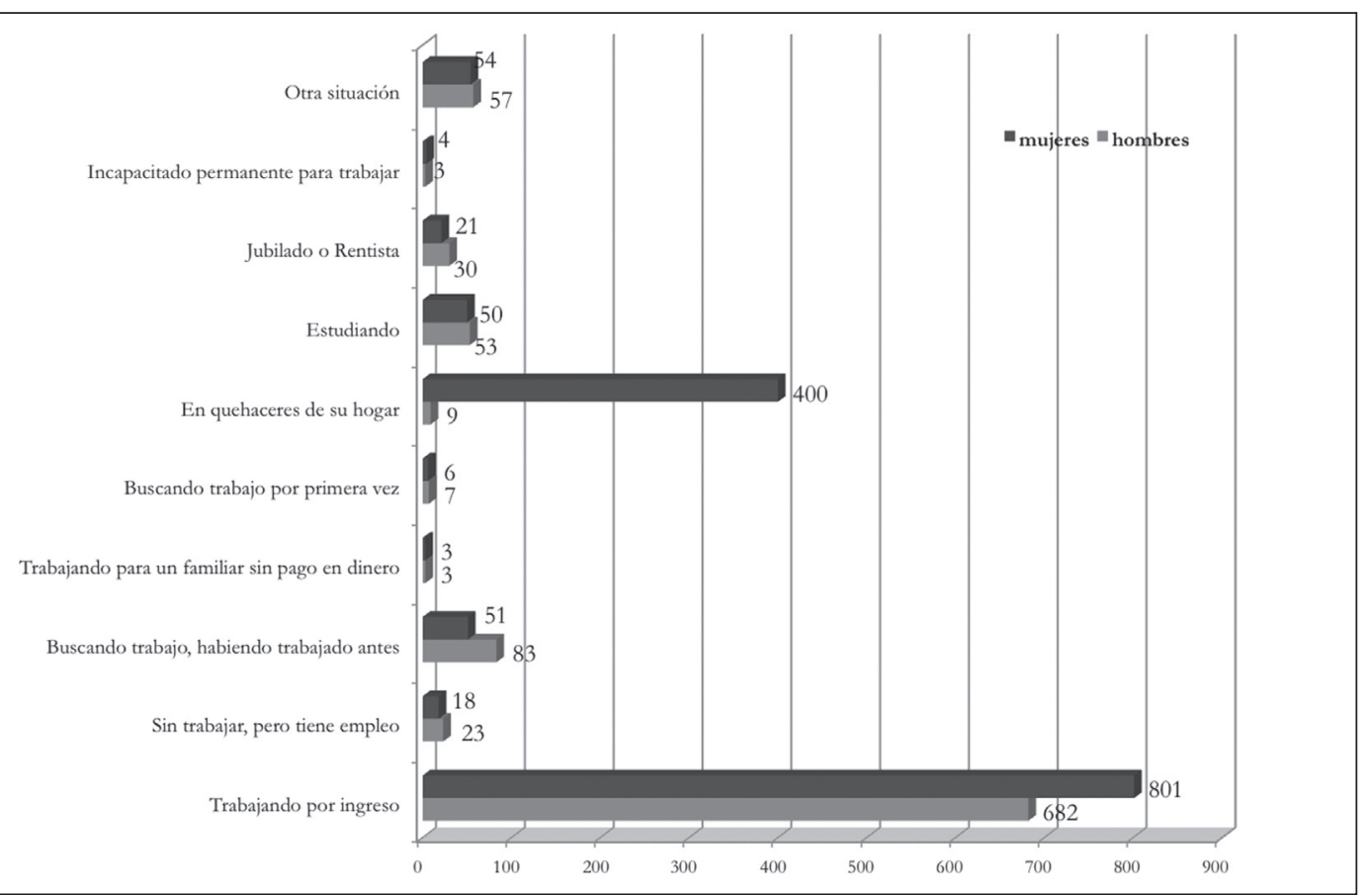

Figura 9. Situación laboral de los migrantes peruanos en la actual región de Tarapacá (comunas de Iquique, Camiña, Pica, Pozo Almonte, Huara y Colchane). Censo 2002. 


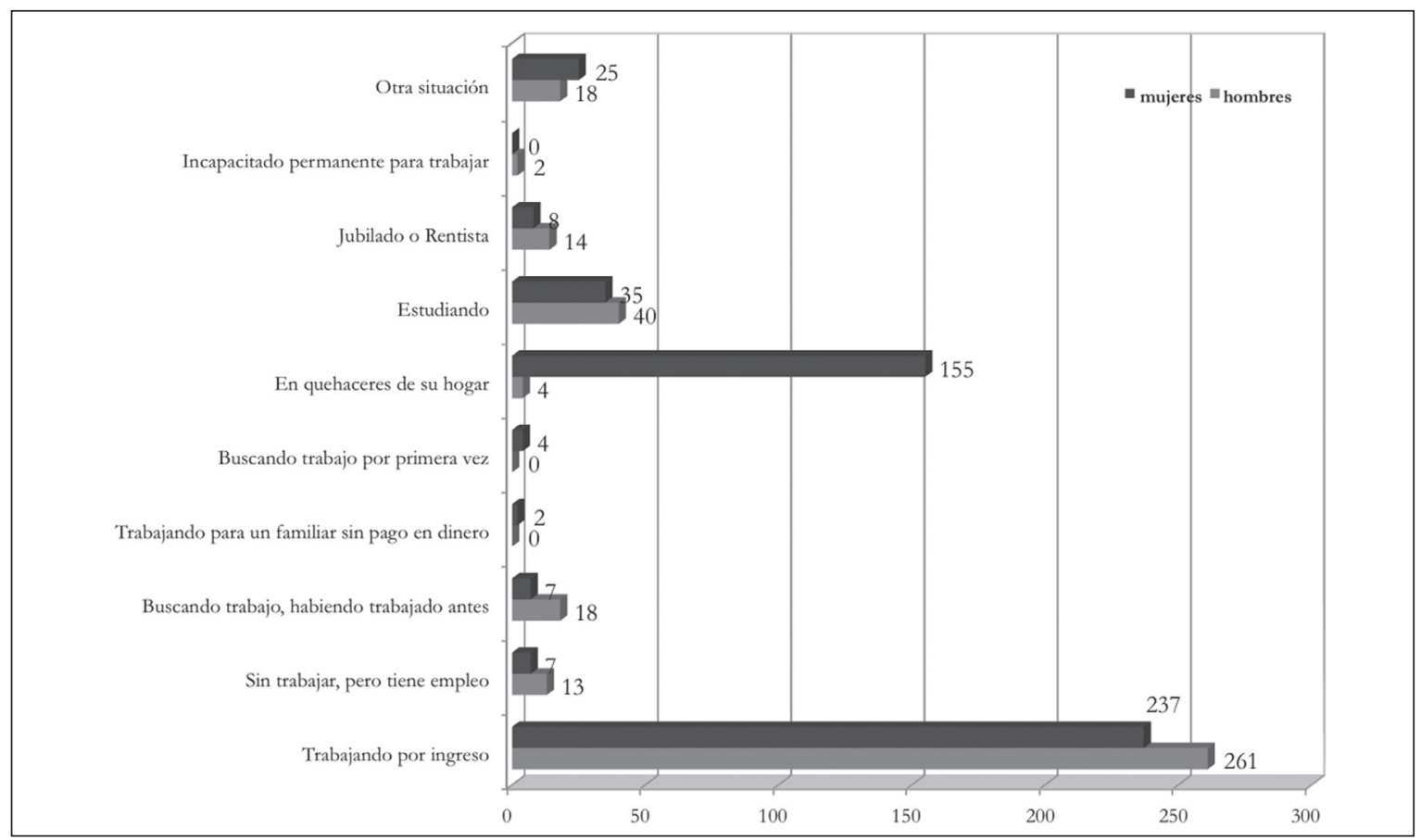

Figura 10. Situación laboral de los migrantes peruanos en la región de Antofagasta. Censo 2002.

155 declararon ser amas de casa, contra 237 trabajando "puertas afuera". En la región Metropolitana, 2.736 peruanas trabajaban en sus propios hogares, contra 12.004 trabajando por ingresos. Pese a que el número absoluto de peruanas trabajando como amas de casa en la región Metropolitana sea elevado -si lo comparamos con los números absolutos encontrados en las regiones del Norte Grande, lo que nos importa aquí es que la proporción de este número en relación al total de peruanas, y en especial en relación a las peruanas que trabajan por ingreso. Esto nos plantea una interesante cuestión que se refiere a que las peruanas en el norte encuentran mecanismos de socialización diferentes, que en parte les permite permanecer en las localidades sin que tengan que ingresar formalmente a los mercados de trabajo locales, manteniéndose en sus hogares. Se puede plantear que esta cifra oculte la realidad de las mujeres que están trabajando ilegalmente y que, por lo tanto, prefieren decir a los encuestadores del censo que trabajan en sus propias residencias. También se puede alegar que en el Norte Grande -dados los vínculos y redes sociales de larga duración que conectan comunidades, ciudades y grupos humanos más allá de las limitaciones de las fronteras nacionales- las mi- grantes peruanas se integran a la sociedad local de otra manera, entre otras cosas a partir de vínculos matrimoniales con parejas chilenas. Sea como fuera, el alto índice de mujeres peruanas trabajando en su propio hogar en el norte llama la atención respecto a una diferencia de inserción económico-social que debe ser explorada a partir de investigaciones cualitativas.

\section{* Apuntes de cara al futuro: dimensiones, PREGUNTAS Y POSIBLES CAMPOS DE INVESTIGACIÓN}

El artículo nos enfrenta a algunos de los ámbitos abiertos para la discusión acerca de las migraciones internacionales en Chile. Por un lado, nos hemos centrado sobre el tema de los espacios geográficos de la investigación. Allí nos encontramos con una primacía de la producción académica de los estudios migratorios en el espacio metropolitano de Santiago, elemento que invisibiliza la dinámica contemporánea y la profundidad temporal de los flujos migratorios en el norte del país -lo que en gran medida apunta hacia la reproducción de naciona- 


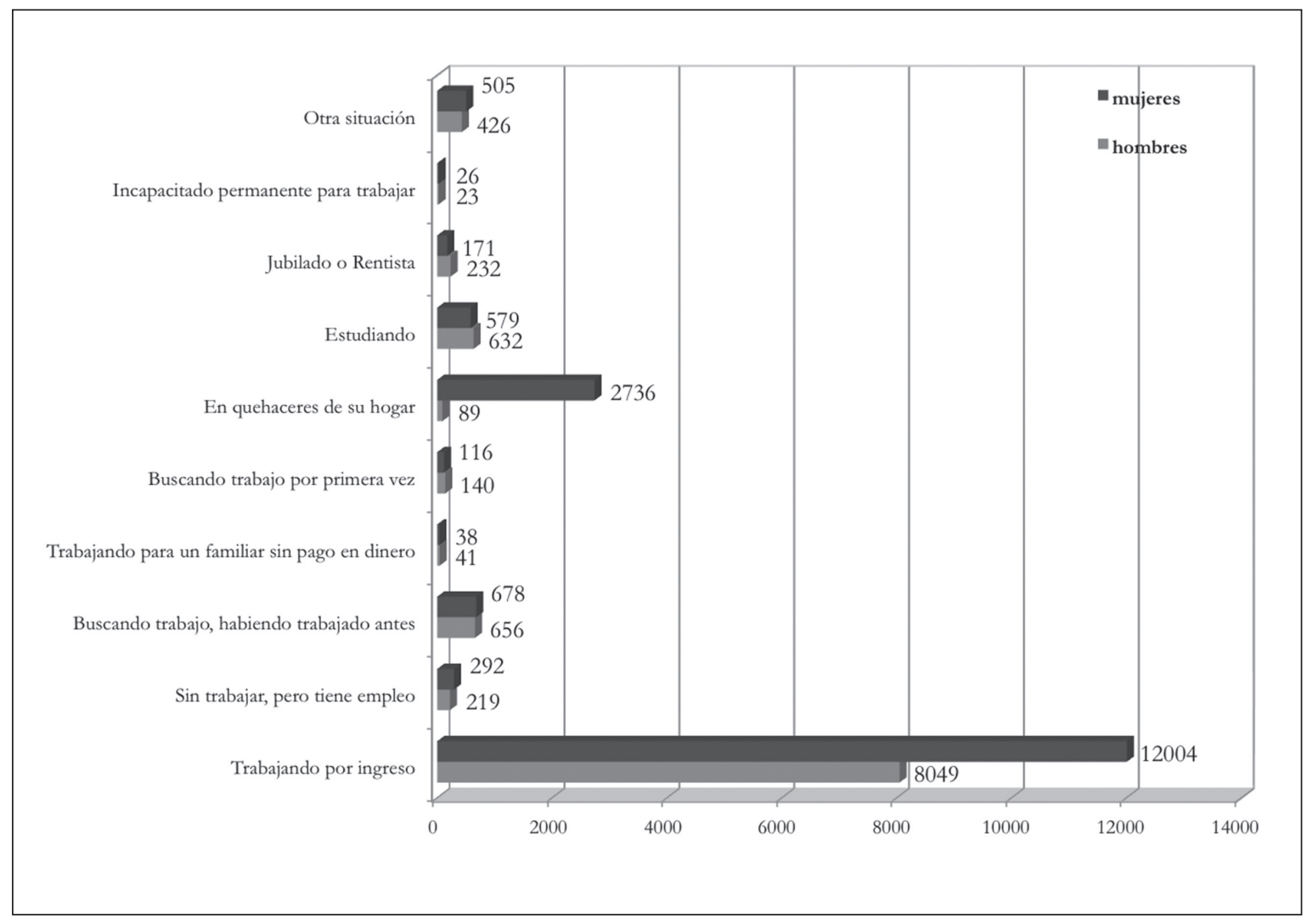

Figura 11. Situación laboral de los migrantes peruanos en la región Metropolitana. Censo 2002.

lismos metodológicos en los recientes estudios acerca de la migración peruana en territorio chileno. Estos nacionalismos metodológicos implican problemas epistemológicos sustanciales en relación a la manera como los investigadores "focalizan" los fenómenos estudiados. De manera general, los recientes estudios sobre peruanos en Chile reinciden en distorsiones del foco analítico que derivan de un no adecuado paso entre la fase empírica del trabajo y el análisis resultante de ésta. Ellos operan una "transvaluación" [transvaluation], es decir, asumen que los elementos observados en el estudio de caso -que dependen marcadamente de un contexto específico, con su específico set de relaciones, movimientos y ubicacionesson representativos de realidades, relaciones, territorios y fenómenos más amplios de lo que realmente pueden representar, definir o significar (Appadurai 2000: 150). No se trata de una operación crítica de transición de contextos micro-sociales hacia macro-sociales, como lo que se propone desde metodologías como el Extended Case
Method (Burawoy 1998: 5). Es más bien un proceso en que se asume de manera acrítica y natural la representatividad de Santiago, y su legitimidad epistémica de "centro" que ilustra todo lo nacional, y que en gran medida tiene autoridad de significación sobre las demás regiones (periféricas) del país.

A partir de hacer patente la existencia de un proceso de invisibilización de la frontera norte chilena en los estudios actuales sobre los procesos migratorios intrarregionales latinoamericanos, podemos indagar en una serie de fenómenos sociales sui generis que han pasado desapercibidos. Nos planteamos una multiplicidad de interrogantes que futuros estudios de caso sobre la migración peruana y también boliviana en el norte de Chile debieran considerar: ¿qué dinámicas particulares de flujo migratorio se producen en los territorios chilenos marcados por las fronteras políticas con Perú, Bolivia y Argentina? ¿En qué se diferencian las relaciones 
de alteridad y/o otredad entre los sujetos ("migrantes" y "autóctonos") cuando estos se relacionan en un contexto de frontera y cuando se relacionan en un contexto central chileno? ¿En qué medida los diferentes ciclos económicos en el norte de Chile -y en nuestro caso el actual protagonismo de la inversión del capital minero internacional en el área-, marcan también la especificidad de los flujos internacionales en esta región, diferenciándolos de los que se dirigen a los territorios centrales chilenos?

Un segundo campo de análisis a desarrollar se refiere justamente a la profundidad histórica de los flujos humanos en esta región fronteriza. Los estudios de caso de la actual migración internacional en el Norte Grande debieran enfrentarse a la necesidad de recuperar los procesos históricos en la zona, recobrando el papel fundamental de la economía salitrera, de la Guerra del Pacífico y de las delimitaciones de las fronteras nacionales tras el conflicto. Muchos de los procesos empezados a raíz del término del conflicto siguen operando en este territorio, influenciando la movilidad humana y la manera como ésta se representa en los imaginarios locales. Habrá que indagar, por ejemplo, en el papel de la política estatal de chilenización en estos territorios tardíamente incorporados al espacio nacional, recuperando no solamente el papel de los nacionalismos en la construcción de estas fronteras, sino también su incidencia en la adscripción de prácticas culturales (entre las cuales la movilidad que ancestralmente caracteriza la vida en estos espacios).

Por otro lado, nuestra preocupación hacia las mujeres, hacia su protagonismo migratorio en un contexto dominado históricamente por las migraciones laborales masculinas (asociadas a la economía de la guerra en el siglo XIX, y a la economía salitrera en el siglo XX), nos hace reflejar la incorporación del Norte Grande chileno en unos ciclos de flexibilización e internacionalización de la mano de obra que son, en última instancia, globales. En este sentido, las mujeres peruanas - pero también las bolivianas, colombianas, ecuatorianas y argentinas-que actualmente llegan a las regiones del norte activan con sus itinerarios migrantes las redes y procesos que están globalizando estas localidades. Y lo hacen de manera circunstancialmente diferente a lo que ocurre con la región Metropolitana de Chile, donde la globalización se vincula a procesos de otra naturaleza, algunos de los cuales más vinculados a la actuación del capital financiero internacional, a la transformación de Santiago en una "ciudad global" (en los términos de Sassen 1986), y a la actuación intensa de los medios de comunicación internacional. Así, la marca de inclusión de estas regiones del norte de Chile a los circuitos globales viene fuertemente influenciada por una condición de género, por la precarización y por la denegación del acceso a la ciudadanía de las mujeres empleadas en servicios de la reproducción social. Esta realidad tiene unas repercusiones económicas, sociales, políticas y culturales a niveles locales que debieran ser consideradas como centrales en los estudios de caso llevados a cabo en el norte chileno.

En el marco de futuros estudios sobre las mujeres peruanas en el norte, cabría indagar el tipo de relaciones de género en las que están insertadas. Habría que observar si la experiencia migrante promueve un proceso de salida al mundo productivo que las libera del trabajo reproductivo, o si se constituye como una sobrecarga laboral (como la acumulación de la labor reproductiva y productiva). Estudios cualitativos también debieran cuestionar acerca del impacto de los ingresos de estas mujeres en la vida de sus hijos e hijas, y en cómo estructuran sus familias y sus roles familiares en una condición transnacional.

Así, en la línea de la exploración arriba presentada, nos interesa precisamente abogar por la necesidad de distinguir la singularidad de las migraciones en el norte en aspectos que van desde los distintos capitales sociales y económicos que los colectivos migrantes ponen en movimiento, en el rol que juegan las pertenencias y adscripciones étnicas (en tanto sostenedoras de la construcción de un campo o tejido social comunitario en gran parte ausentes en la capital), y en la producción de un campo transnacional que en ocasiones se sirve de la institucionalidad estatal, y en otras organiza su dinámica subvirtiendo la misma. Esperamos que el debate que aquí incentivamos contribuya a la focalización de la figura femenina inmigrante en el norte de Chile, permitiendo por tanto que la mirada investigadora cruce las fronteras que tan a menudo los migrantes dislocan. 


\section{* Referencias citadas}

ACOSTA, E., 2011. Valorar los cuidados al estudiar las migraciones: la crisis del trabajo de cuidado y la feminización de la inmigración en Chile. En Mujeres inmigrantes en Chile iMano de obra o trabajadoras con derecho?, C. Stefoni (Ed.), pp. 193-228. Editorial de la Universidad Alberto Hurtado, Santiago.

ALICEA, M., 1997. A Chambered Nautilus: The Contradictory Nature of Puerto Rican Women's Role in the Social Construction of a Transnational Community. Gender and Society 11 (5): 597-626.

ALMAN, L., 2011. Capacitación y movilidad laboral de trabajadoras domésticas peruanas en Santiago de Chile. En Mujeres inmigrantes en Chile. ¿Mano de obra o trabajadoras con derecho?, C. Stefoni (Ed.), pp. 273-310. Editorial de la Universidad Alberto Hurtado, Santiago.

APPADURAI, A., 2000. Modernity at Large. Cultural Dimensions of Globalization. University of Minnesota Press, Minneapolis/ London.

ARANDA, E. M., 2003. Global Care Work and Gendered Constraints: The Case of Puerto Rican Transmigrants. Gender and Society $17(4): 609-626$.

ARAYA M., 2007. Migrantes peruanos en el Chile contemporáneo. Cuaderno de Trabajo (Universidad de Chile) 4: 23-28.

ARAÚJO, K., M. C. LEGUA, y L. OSSANDÓN, 2002. Migrantes andinas en Chile. El caso de la migración peruana. Fundación Instituto de la Mujer, Santiago, pp. 1-47.

ARRIAGADA, I., y M. MORENO, 2011. La constitución de las cadenas globales de cuidado y las condiciones laborales de las trabajadoras peruanas en Chile. En Mujeres inmigrantes en Chile. ¿Mano de obra o trabajadoras con derecho?, C. Stefoni (Ed.), pp. 149192. Editorial de la Universidad Alberto Hurtado, Santiago.

BÄHR, J., 1980. Migraciones en el Norte Grande de Chile. Resultados de un análisis de movimientos migratorios entre los años 1965 y 1970. Revista de Geografía Norte Grande 7: 3-20.

BURAWOY, M., 1998. The Extended Case Method. Sociological Theory $16(1): 4-33$.

2000. Introduction: Reaching for the Global. En Global Etnography. Forces, Connections and Imaginnations in a Postmodern World. T. Gowan y S. Ó. Riain (Eds.), pp. 1: 40. University of California Press, Berkeley - Los Angeles.

CABIB, I.M., y C. MORA DEL VALLE, 2011. Capital social e inclusión laboral. Una aproximación a las trayectorias de ascendencia laboral de migrantes peruanos en Chile. Polis 10 (29): 147-163.
CANO, V., y M. SOFFIA, 2009. Los estudios sobre migración internacional en Chile: apuntes y comentarios para una agenda de investigación actualizada. Papeles de Población 61: 129-167.

CASTLES, S., y M. J. MILLER, 2004. La era de la migración. Movimientos internacionales de población en el mundo moderno. UAZ/ INM/ Fundación Colosio, México D.F.

CONGRESO NACIONAL DE CHILE, 2007. Historia de la Ley 20.175: Crea la XV Región de Arica y Parinacota y la provincia del Tamarugal en la Región de Tarapacá. Santiago, Biblioteca del Congreso Nacional de Chile. En http://www.ben.cl/histley/lfs/ hdl-20175/HL20175.pdf

DEM (2010). Informe Anual. Santiago, Departamento de Extranjería y Migración-Ministerio del Interior. Gobierno de Chile. En http://www.extranjeria.gov.cl/filesapp/Informe\%2oEstimacion\%20Poblacion\%2oExtranjeros\%202008.pdf

DUCCI, M. E., y S. L. ROJAS, 2010. La pequeña Lima: Nueva cara y vitalidad para el centro de Santiago de Chile. Eure 36 (108): 95-121.

ERAZO V. C., 2009. Situación social de los inmigrantes latinoamericanos en la ciudad de Antofagasta, Chile. Hombre y Desierto. Una perspectiva cultural, 15. Instituto de Investigaciones Antropológicas - FACSO/ Universidad de Antofagasta.

ESCRIVÁ, Á., 2005. Peruanos en España ¿De migrantes a ciudadanos? En El quinto suyo. Transnacionalidad y formación diaspórica en la migración peruana, U. D. Berg y K. Paerregaard (Eds.), pp. 133-171. Instituto de Estudios Peruanos, Lima.

GARCÉS, A., 2007. Entre lugares y espacios desbordados. Formaciones urbanas de la migración peruana en Santiago de Chile. Serie Documentos. Escuela de Sociología - Universidad Central de Chile 2: 5-22.

2010. Movimientos y Localizaciones de la migración peruana en Santiago de Chile. Tesis doctoral. Departamento de Antropología Social, Universidad Autónoma de Madrid, España.

2011. De enclave a centralidad. Espacio urbano, comercio y migración peruana en Santiago de Chile. Gazeta de Antropología, 27 (2): Artículo 38, s/n.

2012. Localizaciones para una espacialidad. Territorios de la migración peruana en Santiago de Chile. Chungara 44 (1): 163-175.

GERBAUdO SUÁREZ, D., C. GOLÉ, y C. PIERINI, 2010. Migrantes y fronteras: estrategias de mujeres peruanas frente al fenómeno de la ilegalidad. KULA. Antropólogos del Atlántico Sur 3: 41-53. 
GLICK SCHILLER, N., L. BASCH, y C. BLANC-SZANTON, 1995. From Immigrant to Transmigrant: Theorizing Transnational Migration. Anthropological Quarterly 68 (1): 48-63.

GODOY, L., 2007. Fenómenos migratorios y género: identidades 'remodeladas'. Psykhe 16 (1): 41-51.

GOLTE, J., y N. ADAMS, 1990. Los caballos de Troya de los invasores. Estrategias campesinas en la conquista de la Gran Lima. Instituto de Estudios Peruanos, Lima.

GONZÁLEZ MIRANDA, S., 2009. El Norte Grande de Chile y sus dos triples fronteras: Andina (Perú, Bolivia y Chile) y Circumpuneña (Bolivia, Argentina y Chile). Cuadernos interculturales 7 (13): 27-42.

GONZÁLEZ PIZARRO, J. A., 2008. La emigración boliviana en la pre cordillera de la región de Antofagasta, 1910-1930. Redes sociales y estudios de caso. Revista de Ciencias Sociales Universidad Arturo Prat 21: 61-85.

GREBE VICUÑA, M. E., 1986. Migración, identidad y cultura aymara: puntos de vista del actor. Chungara 16-17: 205-223.

2003. Procesos migratorios, identidad étnica y estrategias adaptativas en las culturas indigenas de Chile: una perspectiva preliminar. Biblioteca Virtual Universal - Universidad de Chile, Santiago.

GUERRERO COSSIO, V., 2006. El espacio social urbano en Iquique: el impacto del capital minero. Revista de Ciencias Sociales UNAP 17: 41-59.

GUNDERMANN K., H. y GONZÁLEZ C., H., 2009. Sociedades indígenas y conocimiento antropológico. Aymaras y atacameños del siglo XIX al XX. Chungara 41 (1): 113-164.

GUNDERMANN, H., y J. I. VERGARA, 2009. Comunidad, organización y complejidad social andinas en el norte de Chile. Estudios Atacameños 38: 107-126.

HOLPER, D., 2002. Distressed Bodies, Shattered Selves. Illness among Peruvian live-in Nanies in Santiago de Chile (An Explorative Study). Tesis doctoral. Leiden University Medical Center, Leiden, The Netherlands.

HONDAGNEU-SOTELO, P., 2000. Feminism and Migration. Annals of the American Academy of Political and Social Science 571: 107-120.

HONDAGNEU-SOTELO, P., y E. AVILA, 1997. I'm Here, but I'm There. The Meanings of Latina Transnational Motherhood. Gender and Society 11 (5): 548-571.
HUGO, G., 2000. Migration and Women's Empowerment. En Women's Empowerment and Demographic Processes: Moving Beyond Cairo, B. Harriet y S. Gita (Eds.), pp. 287-317. Oxford University Press, Oxford.

IMILAN, W., 2007. Socaireños en movimiento. Atacameños y Calama. Estudios Atacameños 33: 105-123.

JENSEN, M. F., 2009. Inmigrantes en Chile: la exclusión vista desde la política migratoria chilena. En Temáticas migratorias actuales en América Latina: remesas, políticas y emigración, Eduardo Bologna (Org.), pp. 105-130. Serie Investigaciones, 7, ALAP, Rio de Janeiro.

JENSEN, M. F., y X. VALBENITO, 2010. De inclusiones y exclusiones: una perspectiva de la inmigración desde la asociatividad en Chile. Miradas en Movimiento III: 6-38.

LAHOZ, S., 2011. Atribuciones identitarias de las mujeres peruanas en Santiago. En Mujeres inmigrantes en Chile. ¿Mano de obra o trabajadoras con derecho?, C. Stefoni (Ed.), pp. 109-145. Editorial de la Universidad Alberto Hurtado, Santiago.

LARRAÍN M., P. 2000. Mujeres peruanas tras las huellas de los soldados. Revista de Historia (Santiago) 33.

LEVITT, P., y N. GLICK-SCHILLER, 2004. Perspectivas internacionales sobre la migración: conceptualizar la simultaneidad. Migración y Desarrollo 3: 60-91.

LIPSZYC, C., 2004. Feminización de las Migraciones: Sueños y realidades de las mujeres migrantes en cuatro países de América Latina. Actas del Encuentro Caminar sin Miedos. Montevideo, 13-15 abril 2004: 1-23.

LOYO, M. G., y M. D. VELÁSQUEZ, 2009. Aspectos jurídicos y económicos del trabajo doméstico remunerado en América Latina. En Trabajo doméstico: un largo camino hacia el trabajo decente, C. Mora y M. E. Valenzuela (Eds.), pp. 21-70. OIT, Santiago.

LUQUE, J. C., 2004. Transnacionalismo y enclave territorial étnico en la configuración de la ciudadanía de los migrantes peruanos en Santiago de Chile. Enfoque 3: 81-102.

2005. Nacionalismo, identidad nacional y sociedad civil en la configuración de la ciudadanía de los migrantes peruanos en la ciudad de Santiago de Chile. ICEA 1 (1): 129-148.

2007. Asociaciones políticas de inmigrantes peruanos y la 'Lima Chica' en Santiago de Chile. Migraciones Internacionales 4 (2): 121-150. 
2009. La producción de la ciudadanía en la era de la migración: el caso de las asociaciones políticas de los peruanos en Santiago de Chile (1996-2006). Ánfora 16 (27): 63-85.

MAGLIANO, M. J., y S. M. ROMANO, 2011. El desarrollo y las migraciones femeninas en la agenda política sobre migraciones internacionales: universalismo etnocéntrico y colonialidad de género. En Migraciones internacionales contemporáneas. Estudios para el debate, C. Pizarro (Ed.), pp. 39-62. Ciccus, Buenos Aires.

MARCUS, G. E., 1995. Ethnography in/of the World System: The Emergence of Multi-Sited Ethnography. Annual Review of Anthropology 24: 95-117.

MARTÍNEZ-LABRÍN, S., 2006. Representaciones sociales, inmigración y mujeres: hegemonía y polisemia. Theoria 15 (2): 61-67.

MARTÍNEZ-PIZARRO, J., 2003. El mapa migratorio de América Latina y El Caribe, las mujeres y el género. Serie Población y Desarrollo, CELADE-CEPAL: http:/www.oas.org/atip/Migration/ CEPAL\%2oStudy\%20on\%2oMigration.pdf.

2007. Feminización de las migraciones en América Latina: discusiones y significados para políticas. En Conferencia Regional sobre Migración (CRM). Memoria Seminario Mujer y Migración, 19-20 de julio de 2007: www.crmsv.org/pagina_n37.htm

2009. Notas sobre las características de la fuerza laboral migrante en las Américas. CELADE-CEPAL: http: //www.eclac.cl/ cgi-bin/getProd.asp?xml=/celade/noticias/documentosdetrabajo/9/36579/P36579.xml\&xsl=/celade/tpl/p38f.xsl

MÉNDEZ, L., y M. CÁRDENAS, 2012. Hacia una construcción de un modelo comprensivo de análisis de la 'situación de migración' de mujeres sudamericanas en Chile. Psicoperspectivas: Individuo y Sociedad 11 (1): 252-272.

MERINO, A., 2003. Relaciones entre gente, cultura y lugar en el fenómeno migratorio contemporáneo: los peruanos en España. Revista de Indias LXIII (229): 737-756.

MIGNOLO, W., 1996. Herencias coloniales y teorías postcoloniales. En Cultura y Tercer Mundo: Cambios en el Saber Académico, B. Gonzáles Stephan (Ed.), pp. 99-136. Nueva Sociedad, Venezuela.

MILLS, M. B., 2003. Gender and Inequality in the Global Labor Force. Annual Review of Anthropology 32: 41-62.

MITCHELL, J. C., 2006. Case and Situation Analysis. En The Manchester School. Practice and Ethnographic Praxis in Anthropology, T. M. S. Evens y D. Handelman (Eds.), pp: 13-22.
MORA, C., 2008. Globalización, género y migraciones. Polis 7(20): 285-297.

MORA, C., y M. E. VALENZUELA, 2009. Introducción. En Trabajo doméstico: un largo camino hacia el trabajo decente, C. Mora y M. E. Valenzuela (Eds.), pp: 11-21. OIT, Santiago.

MUJICA, J., 2004. El desafio de la solidaridad: condiciones de vida y trabajo de los migrantes peruanos en Chile. OIT, Lima.

NAVARRETE, B., 2007. La quinta oleada migratoria de peruanos a Chile: los residentes legales. Enfoques 7: 173-195.

NYBERG, N., 2008. La familia transnacional de latinoamericanos/as en Europa. En América Latina migrante: Estado, familias, identidades, G. Herrera y J. Ramírez (Eds.), pp. 259-280. Quito, FLACSO-Ecuador.

NÚÑEZ, L., y D. HOLPER, 2005. 'En el Perú, nadie se muere de hambre': pérdida de peso y prácticas de alimentación entre trabajadoras domésticas peruanas. En El quinto suyo. Transnacionalidad y formación diaspórica en la migración peruana, U. D. Berg y K. Paerregaard (Eds.), pp. 291-313. Instituto de Estudios Peruanos, Lima.

NÚÑEZ, N. R., y C. E. TORRES, 2007. Mujeres migrantes peruanas y salud reproductiva. Usuarias de consultorios de salud de la Zona Norte de la Región Metropolitana. Fundación Instituto de la Mujer, Santiago.

PAERREGAARD, K., 2005. Callejón sin salida: estrategias e instituciones de los peruanos en Argentina. En El quinto suyo. Transnacionalidad y formación diaspórica en la migración peruana, U. D. Berg y K. Paerregaard (Eds), pp. 231-26o. Instituto de Estudios Peruanos, Lima.

2006. La migracion femenina: estrategias de sostenimiento y movilidad social entre peruanos en España y Argentina. Anthropológica XXV(25): 61-82.

PARELLA, S., 2003. Mujer, migrante y trabajadora: la triple discriminación. Anthropos, Barcelona.

2005. Segregación laboral y vulnerabilidad social de las mujeres inmigrantes a partir de la interacción entre clase social, género y etnia. En El uso de las políticas sociales por las mujeres inmigrantes, C. Solé y L. Flaquer (Eds.), pp. 97-138. Instituto de la Mujer, Madrid.

2007. Los vínculos afectivos y de cuidado en las familias transnacionales: Migrantes ecuatorianos y peruanos en España. Migraciones Internacionales 4 (2): 151-188. 
PAVEZ-SOTO, I., 2010. Migración infantil: rupturas generacionales y de género. Las niñas peruanas en Barcelona y Santiago de Chile. Tesis doctoral. Facultat de Ciéncies Politiques i Sociologia, Departament de Sociologia, Universidad Autónoma de Barcelona.

PEDONE, C., 2011. Nuevas formas de organización familiar: la migración ecuatoriana hacia España. En Migraciones internacionales contemporáneas. Estudios para el debate, C. Pizarro (Ed.), pp. 63-75. Ciccus, Buenos Aires.

PIZARRO, C., 2011. Introducción. En Migraciones internacionales contemporáneas. Estudios para el debate, C. Pizarro (Ed.), pp. 5-17. Ciccus, Buenos Aires.

POBLETE, M. R., 2006. Educación intercultural: teorías, politicas y prácticas. La migración peruana en el Chile de hoy. Nuevos escenarios y desafíos para la integración. Tesis doctoral. Departamento de Antropología Social y Cultural - Universidad Autónoma de Barcelona.

PÓO, X. F., 2009. Imaginarios sobre migración peruana en la prensa escrita chilena: una mirada a la instalación de la agenda de la diferencia. Faro 5 (9): 1-9.

RIVAS, A.M., y H. GONZÁLEZ, 2010. Familias transnacionales colombianas: Transformaciones y permanencias en las relaciones y prácticas de género. Catarata, Madrid.

RODGERS, J., 2009. Cambios en el servicio doméstico en América Latina". En Trabajo doméstico: un largo camino hacia el trabajo decente, C. Mora y M. E. Valenzuela (Eds.), pp. 71-114. OIT, Santiago.

SALAZAR, G., 2005. Construcción de Estado en Chile (1800-1837). Democracia de los "pueblos". Militarismo ciudadano. Golpismo oligárquico. Editorial Sudamericana, Santiago.

SANTANDER, C. U., 2006. La migración peruana en el contexto del patrón de las corrientes migratorias en Chile: pasado, presente y futuro. LASA Congress 2006, LASA, Puerto Rico.

SASSEN, S., 1986. Notes on the Incorporation of Third World Women into Wage-Labor Through Immigration and Off-Shore Production. International Migration Review 18 (4): 1144-1167.

SCHIAPPACASSE, P., 2008. Segregación espacial y nichos étnicos de los migrantes internacionales en el Área Metropolitana de Santiago. Revista de Geografía Norte Grande 39: 21-38.

SETIÉN, M. L., y E. ACOSTA, 2011. Cuidados y flujos migratorios feminizados sur-norte y sur-sur: Negación de derechos y ciudadanía limitada. Revista Latina de Sociología 1: 182-208.
SOLÉ, C., y S. PARELLA, 2005. Discursos sobre la 'maternidad transnacional' de las mujeres latinoamericanas residentes en Barcelona. En: Mobilitès au Femenine, Tanger, 15-19 noviembre 2005: http://lames.mmsh.univ-aix.fr/Papers/ParellaSole_ES.pdf

STAAB, S., y K. H. MABER, 2006. The Dual Discourse about Peruvian Domestic Workers in Santiago de Chile: Class, Race, and a Nationalist Project. Latin American Politics and Society 48 (1): 87-116.

STEFONI, C., 2002. Mujeres peruanas en Chile. Papeles de Población 33: 118-135.

2005. Inmigrantes Transnacionales. La formación de comunidades y la transformación en ciudadanos. En El quinto suyo. Transnacionalidad y formación diaspórica en la migración peruana, U. D. Berg y K. Paerregaard (Eds.), pp. 261-289. Instituto de Estudios Peruanos, Lima.

2009. Migración, género y servicio doméstico. Mujeres peruanas en Chile. En Trabajo doméstico: un largo camino hacia el trabajo decente, M. E. Valenzuela y C. Mora (Eds.), pp. 191-232. OIT, Santiago.

2011. Mujeres inmigrantes en Chile iMano de obra o trabajadoras con derecho? Universidad Alberto Hurtado, Santiago.

STEFONI, C., y R. FERNÁNDEZ, 2011. Mujeres inmigrantes en el trabajo doméstico: entre el servilismo y los derechos. En $\mathrm{Mu}$ jeres inmigrantes en Chile ¿Mano de obra o trabajadoras con derecho?, C. Stefoni (Ed.), pp.43-72. Editorial de la Universidad Alberto Hurtado, Santiago.

TAMAGNO, C., 2005. Entre celulinos y cholulares: prácticas comunicativas y la construcción de vidas transnacionales entre Perú e Italia. En El quinto suyo. Transnacionalidad y formación diaspórica en la migración peruana, U. D. Berg y K. Paerregaard (Eds.), pp. 173-204. Instituto de Estudios Peruanos, Lima.

TAPIA LADINO, M., y V. GAVILÁN, 2006. Diagnóstico de las migraciones fronterizas de la I Región de Tarapacá, Chile. Universidad Arturo Prat, Iquique.

TAPIA LADINO, M., H. GONZÁLEZyA. N. RODRÍGUEZ, 2010. Transformaciones y permanencias en las relaciones y prácticas de género en las familias transnacionales colombianas. En Familias transnacionales colombianas: Transformaciones y permanencias en las relaciones y prácticas de género, A. M. Rivas y H. González (Eds.), pp. 147-194. Catarata, Madrid.

TIJOUX, M. E., 2002. Morderse la lengua y salir adelante. Amérique Latine Histoire et Mémoire. Les Cahiers ALHIM, 5: http://alhim.revues.org/index639.html. 
2007. Peruanas migrantes en Santiago. Un arte cotidiano de la lucha por la vida. Polis $18: \mathrm{s} / \mathrm{n}$.

2011. "Negando al 'otro': el constante sufrimiento de los inmigrantes peruanos en Chile". En Mujeres inmigrantes en Chile ¿Mano de obra o trabajadoras con derecho?, C. Stefoni (Ed.), pp. 15-42. Editorial de la Universidad Alberto Hurtado, Santiago.
WAGNER, H., 2008. Maternidad transnacional: discursos, estereotipos, prácticas. En América Latina migrante: Estado, familias, identidades, G. Herrera y J. Ramírez (Eds.), pp. 325-342. FLACSO-Ecuador, Quito.

YPEIJ, A., 2000. Producing against Poverty, Female and Male Micro-entrepreneurs in Lima, Peru. Amsterdam University Press, Amsterdam. 